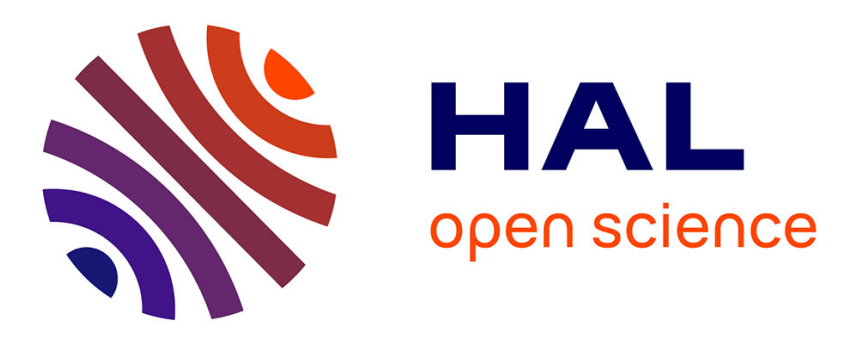

\title{
Coupling statistical indentation and microscopy to evaluate micromechanical properties of materials: Application to viscoelastic behavior of irradiated mortars
}

\author{
Benoit Hilloulin, Maxime Robira, Ahmed Loukili
}

\section{To cite this version:}

Benoit Hilloulin, Maxime Robira, Ahmed Loukili. Coupling statistical indentation and microscopy to evaluate micromechanical properties of materials: Application to viscoelastic behavior of irradiated mortars. Cement and Concrete Composites, 2018, 94, pp.153 - 165. 10.1016/j.cemconcomp.2018.09.008 . hal-01938271

\section{HAL Id: hal-01938271 \\ https://hal.science/hal-01938271}

Submitted on 28 Nov 2018

HAL is a multi-disciplinary open access archive for the deposit and dissemination of scientific research documents, whether they are published or not. The documents may come from teaching and research institutions in France or abroad, or from public or private research centers.
L'archive ouverte pluridisciplinaire HAL, est destinée au dépôt et à la diffusion de documents scientifiques de niveau recherche, publiés ou non, émanant des établissements d'enseignement et de recherche français ou étrangers, des laboratoires publics ou privés. 
1 Coupling statistical indentation and microscopy to evaluate micromechanical properties of materials: application to viscoelastic behavior of irradiated mortars

$4{ }^{a}$, Institut de Recherche en Génie Civil et Mécanique (GeM), UMR-CNRS 6183, Ecole Centrale

5 de Nantes, 1 rue de la Noë, 44321 Nantes, France - e-mail: benoit.hilloulin@ec-nantes.fr;

6 ahmed.loukili@ec-nantes.fr

$7{ }^{b}$ SUBATECH, Unité Mixte de Recherche 6457, École des Mines de Nantes, CNRS/IN2P3,

8 Université de Nantes, BP 20722, 44307 Nantes cedex 3, France - e-mail:

9 robira@subatech.in2p3.fr

$10{ }^{c}$ Tractebel Engineering - Le Delage, 5 rue du 19 Mars 1962, 92622 Gennevilliers CEDEX, 11 France

12

$14 \quad{ }^{*}$ Corresponding author: Tel.: + $33(0) 240371661$

17 Highlights

18 - Data mining principles applied to materials can lead to substantial improvements in 19 the properties identification process.

20 - Coupling indentation and optical analysis reduces identified phase properties' 21 variability.

22 - $\gamma$-irradiated mortar samples exhibit greater creep modulus and hardness and lower creep characteristic time than references. 


\section{Abstract}

26 In this work, an original method coupling statistical indentation and 3D microscope

27 image analysis for heterogenous materials characterization is developed. Statistical

28 microindentation test results performed on $\gamma$-irradiated and pristine mortar specimens

29 are presented and analyzed using a clustering data mining technique. The outputs are

30 compared with the phase identification from 3D image analysis to effectively reduce

31 uncertainties in the material properties of one of the phases (cement paste). With respect

32 to the effects of irradiations on cementitious materials, a significant increase of cement

33 paste creep modulus and hardness, and a significant decrease of creep characteristic

34 time, are highlighted after an exposition of $257 \mathrm{kGy}$ at $8.5 \mathrm{~Gy} / \mathrm{min}$. Young's modulus

35 of the cement paste is not significantly affected. These results confirm macroscopic

36 concrete creep observations presented in previous studies fitted with dose-dependent

37 logarithmic laws.

40 Keywords: Indentation, Cement Paste (D), Mechanical properties (C), Creep (C), 41 Radioactive Waste (E), Image analysis (B).

\section{Introduction}

44 The macroscopic mechanical properties of concrete mainly depend on micro45 mechanical properties of its binding phase (i.e., the cement paste) and more particularly on the calcium silicate hydrate (CSH) gel, which exhibits significant local variations.

47 For some years, microindentation and nanoindentation have been widely investigated to

48 characterize elasto-plastic and creep properties of cementitious materials [1-4]. 
49 Indentation elastic parameters can then be input in homogenization schemes to

50 determine concrete elastic properties [5-7].

51 According to Oliver and Pharr theory [8], the initial elastic unloading part of indentation

52 curves can be analyzed to determine the indentation modulus and the indentation

53 hardness of homogenous materials. Because cement paste is highly heterogenous, even

54 at very small length scales, statistical nanoindentation performed at loads leading to

55 penetration depths of some hundreds of nanometers has been developed. Assuming several phases may be indented at the same time, statistical indentation's main objective is to collect enough data points to apply a deconvolution algorithm giving the individual phase properties $[9,10]$. However, two main critical aspects were identified regarding 59 the application of statistical indentation technique to cementitious materials [11]: the 60 size of the interaction volume may be larger than the size of the single phases at the risk 61 of creating spurious peaks in the probability density function (PDF) $[12,13]$ as well as micromechanical values depending on the applied load [14], and the deconvolution analysis based on Gaussian Mixture itself may converge to local minima [15].

64 Therefore, coupling indentation results to other techniques identifying the effective 65 nature of the indents is of great interest at different scales: using atomic force microscope [16] or SEM [6, 17, 18]. Coupling nanoindentation and SEM-EDS to filter

67 data points, Chen et al. highlighted the presence of ultra-high density $\mathrm{CSH} / \mathrm{Ca}(\mathrm{OH})_{2}$ nanocomposites in low water-to-cement ratio cement paste by correlating 69 micromechanical properties, e.g. indentation hardness or indentation modulus, to the 70 portlandite volume fraction measured in volumes with approximately the same size as 71 the one investigated through nanoindentation. Localization of indents by imaging 72 techniques can also be used to differentiate the properties of several inclusions $[19,20]$ 73 and eventually map a restricted area depending on the measured mechanical properties 
$74[19,21]$. From the microscale to the macroscale, 3D image analysis of concrete or

75 mortar surface appears to offer a promising field of research for purposes of generating 76 geometric or topological data and supplementing other experimental techniques or 77 providing input for numerical models [22-24].

78 Besides these developments concerning statistical indentation and imaging, it has been 79 found out that the long-term creep properties of concrete specimens are related to the 80 creep properties measured during minute-long microindentation or nanoindentation experiments. Both creep behaviors can be described using logarithmic time-dependent functions with two main variables: creep modulus and creep characteristic time $[7,25$, 26]. Creep modulus of cement paste is linearly correlated with indentation hardness which means that the lower the hardness, the greater the creep strains, though the slope of the regression depends on the material: creep modulus of pure $\mathrm{CSH}$ is greater than the one of cement paste and it decreases with $\mathrm{Ca} / \mathrm{Si}$ ratio [27]. Like macroscopic creep, indentation creep depends on the relative humidity [28].

In the context of nuclear waste disposals and, more generally, in the scope of nuclear safety structures characterization, the assessment of mechanical properties of irradiated

90 concrete is of great interest to speculate over long term behavior of concrete under irradiations. Concrete properties evolutions with radiations have recently been summarized [29]. An extensive literature review ensures that irradiations lead to a 93 decrease of the macroscopic strength of concrete under several types of radiations $(\alpha, \gamma$ and neutrons). The main mechanism behind concrete degradation under $\alpha$-radiation is radiation-induced volumetric expansion (RIVE) of siliceous aggregates [30, 31] at doses

96 greater than a reference dose of around $1 \times 10^{20} \mathrm{n} / \mathrm{cm}^{2}$ [32]. But under pure $\gamma$-radiation 97 (exposition condition of structural concrete element of disposals [33]), degradation mechanisms are not understood yet and there is still a debate whether a reference level 
of $2 \times 10^{5} \mathrm{kGy}$ introduced some decades ago is relevant or not as some recent studies

100 showed degradations after the exposure to lower doses [34, 35]. Water radiolysis

101 triggered by $\gamma$-radiation is supposed to be the main phenomenon responsible of possible

102 degradations located in the cement paste $[36,37]$ and phase alterations occurs only at

103 very high doses of some dozens or even hundreds of MGy [38].Concrete creep under

104 low dose irradiation $(<1 \mathrm{~Gy} / \mathrm{h}[33])$ is one of the major preoccupations concerning

105 long-term behavior of waste disposal infrastructures. To our knowledge, only one study

106 reported the smaller extent of creep of $\gamma$-irradiated concrete under compression, though

107 measurements were carried out over a relatively short period of one year without any

108 repetition [39].

109 The growing use of various data mining techniques in civil engineering and materials

110 science applications is changing the way scientists and engineers are facing issues and

111 creating promising paths of investigation at the same time. Larger datasets can be

112 obtained and the challenge is to find useful and innovative information out of them [40].

113 Data mining techniques are being developed to identify materials properties [41] and

114 even leading to the creation of novel materials. In civil engineering [42], data mining

115 has mainly been used for large scale transportation problems for some years [43].

116 A main objective of the present work is to demonstrate the potential of data mining

117 techniques for material properties identification in civil engineering at a microscale and

118 mesoscale, at the crossroads of materials science and civil engineering. For this purpose,

119 two complementary methods, namely statistical microindentation and microscopy, were

120 performed on mortar specimens and combined to detect hidden data trends. Used

121 together with adequate data mining techniques, microindentation data analysis and

122 optical microscopy image analysis are shown to reduce the uncertainties associated with

123 cement paste mechanical properties identification. An application to the determination 
124 of mechanical properties of $\gamma$-irradiated mortars is then proposed. The first micro

125 mechanical dataset of this type is reported and compared with the only, because tedious,

126 measurement performed on concrete some decades ago [39]. Hundreds of measurement

127 points obtained from 3 irradiated and 3 pristine control specimens are compared to

128 highlight hidden trends due to radiation exposure.

130 2. Materials and methods

\section{$131 \quad 2.1$ Specimens preparation and irradiation conditions}

132 Mortar was prepared with CEM I 52.5 and $0 / 4 \mathrm{~mm}$ calcareous sand (to avoid the

133 activation of alkali-silica reaction by irradiation) with the proportions detailed in

134 Table 1. Any use of organic additives like superplasticizer or demolding oil was

135 avoided to not induce a possible premature degradation by the irradiations. This mortar

136 formulation was determined to be as representative as possible of a high-performance

137 concrete used in nuclear waste storage facility galleries.

138 Six mortar prisms with dimensions of $4 \times 4 \times 16 \mathrm{~cm}^{3}$ were cast in polypropylene molds

139 to avoid any presence of metallic compounds from the molds. After 1 day of curing

140 under sealed conditions in an air-conditioned room at a temperature of $20^{\circ} \mathrm{C}$ and

$14190 \% \mathrm{RH}$, the specimens were demolded. The specimens were further cured in lime-

142 saturated water until the age of 28 days. Mortar prisms were then dried during 14 days

143 in an oven at $45^{\circ} \mathrm{C}$ (a constant mass was measured at 10 days).

144 Half of the mortar prisms (MD-257kGy-I1 to MD-257kGy-I3) were then introduced in 145 an irradiator at ARRONAX $\left({ }^{137} \mathrm{Cs}\right.$ source, $\left.661 \mathrm{keV}, 123.4 \mathrm{TBq}\right)$ at the age of 42 days.

146 Specimens were exposed as close to the source as possible to guarantee a spatially

147 homogenous dosage during 3 weeks. The total $\gamma$ dose received by the specimens was

148 calculated to be around $257 \mathrm{kGy}$ based on a map of the $\gamma$ fluxes in the irradiator realized 
149 by Fricke dosimetry measurement. The other half of the specimens (MD-257kGy-S1 to

150 MD-257kGy-S3), e.g. the control specimens, were kept in an air-conditioned room at 151 relative humidity of around $65 \%$ close to the ones measured in the irradiator at the end 152 of the irradiation period.

153 Table 1. Mortar compositions

\begin{tabular}{ccccc}
\hline Cement & Calcareous Sand 0/4 & Water & W/C & Paste volume \\
$\left(\mathrm{kg} / \mathrm{m}^{3}\right)$ & $\left(\mathrm{kg} / \mathrm{m}^{3}\right)$ & $\left(\mathrm{kg} / \mathrm{m}^{3}\right)$ & & $(\%)$ \\
\hline 566 & 1344 & 270 & 0.43 & 45 \\
\hline
\end{tabular}

155 Several mechanical and chemo-physical tests were performed on these mortars and on

156 other series as well. The results will be presented in future communications but, in the

157 sake of clarity, some results may be evocated in regards to micromechanical results

158 presented herein. No evident carbonation, pore size evolution or hydrated phases

159 transformations were measured. Thus micromechanical properties evolutions may not

160 be attributed to calcite formation in contrast with [44].

161

$162 \quad 2.2$ Indentation setup and theory

163 Microindentation tests were performed during the week following the irradiation period

164 with the main objective of comparing the properties of irradiated and control specimens.

165 Thus, a volume of $2 \times 2 \times 1.5 \mathrm{~cm}^{3}$ was sawn from the middle part of a half of the

$1664 \times 4 \times 16 \mathrm{~cm}^{3}$ broken by three-point bending test. This location was selected to avoid

167 damage due to the three-point bending test. The $2 \times 2 \mathrm{~cm}^{2}$ section was polished with Si-

168 C paper with decreasing particle size $(500,1200,2000,4000)$ using ethanol as polishing

169 liquid. Polishing times were selected around some minutes per paper to limit the risk of 170 aggregate cracking. These times are much shorter than the ones used for 
nanoindentation on cement pastes [45] but were sufficient to obtain a surface roughness

$172 \mathrm{R}_{\mathrm{q}}$ of around $0.5-1 \mu \mathrm{m}$ which is acceptable for micro-indentation with penetration 173 depth of some microns.

174 A typical cement paste area with a typical indent is presented in Fig. 1. As it can be 175 observed, the scale of the indent is larger than the characteristic scale of the 176 microstructure of the cement paste (residual anhydrous clinker size): thus, the 177 performed microindentation tests provided the mechanical properties of the cement 178 paste or the sand, or the interface and not of the individual phases of the cement paste.

179 Microindentation was performed using a Vickers indenter probe over a grid of $18020 \times 20$ points, evenly spaced by $500 \mu \mathrm{m}$ to investigate a representative surface of $1811 \mathrm{x} 1 \mathrm{~cm}^{2}$ of the mortar sample. For each indent, the load was increased linearly over 182 time in $5 \mathrm{~s}$ up to $2000 \mathrm{mN}$, kept constant during the $60 \mathrm{~s}$ holding phase, and decreased 183 linearly over time back to zero in $5 \mathrm{~s}$. The very short loading time was selected to limit 184 creep during this period and do not apparently damaged the sample.

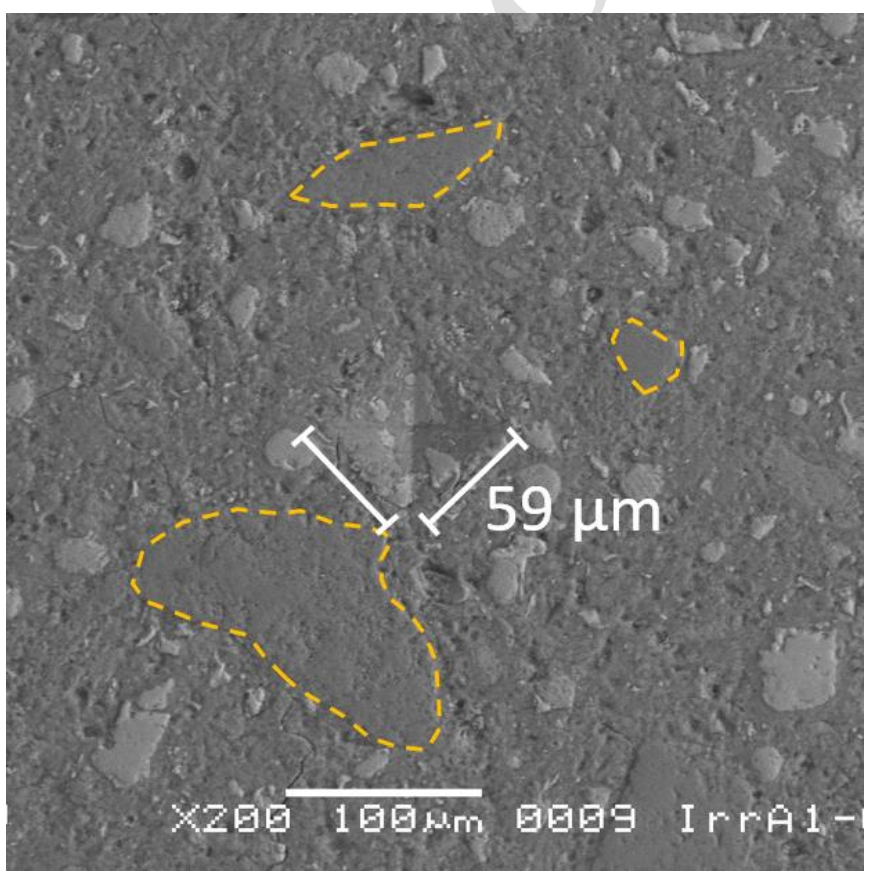


185 Fig. 1. SEM observation of a typical indent located in the cement paste with a width of

$18659 \mu \mathrm{m}$ (small sand fines located near the indent are circled by orange dashed lines).

187

188 Various properties were calculated from the load-penetration curves. First, the

189 indentation hardness depending on the maximum load and the projected contact area:

$$
H_{I T}=\frac{P_{\max }}{A_{p}\left(h_{c}\right)}
$$

190 For Vickers' indenter the projected contact area can be estimated by:

$$
A_{p}\left(h_{c}\right)=24.50 h_{c}^{2}
$$

191 Where $h_{c}$ can be calculated based on maximum indentation depth $h_{\max }$ assuming:

$$
h_{c}=h_{\max }-\varepsilon\left(h_{\max }-h_{r}\right)
$$

192 with $\varepsilon=0.75$ and $h_{\mathrm{r}}$ is the final ideal penetration height can be determined. Martens

193 hardness was also computed according to:

$$
H_{M}=\frac{P_{\max }}{A_{S}(h)}
$$

194 Where $A_{s}(h)$ is the contact area, depending on the indentation depth $h$, defined for a

195 Vickers indenter by:

$$
A_{s}(h)=\frac{4 \sin (\alpha / 2)}{\cos ^{2}(\alpha / 2)} h^{2} \approx 26.43 h^{2}
$$

196 With $\alpha=136^{\circ}$ the top angle of the Vickers pyramid.

197 The Young's modulus $\mathrm{E}_{\mathrm{IT}}$ of the indented material is given by:

$$
M=\frac{E_{I T}}{1-v_{S}^{2}}=\frac{1}{\frac{1}{E_{r}}-\frac{1}{M_{\text {ind }}}}
$$

198 Where $M$ denotes the indentation modulus, $\mathrm{M}_{\text {ind }}=1140 \mathrm{GPa}$ the modulus of the

199 indenter, $v_{s}$ the Poisson ratio of the material (considered equal to 0.2, a possible 
200 variation of some percent of EIT may be induced for other values of Poisson ratio) and

$201 \mathrm{E}_{\mathrm{r}}$ is the reduced modulus which is determined assuming:

$$
E_{r}=\frac{1}{2}\left(\frac{d P}{d h} \sqrt{\frac{\pi}{A}}\right) \text { at } h=h_{\max }
$$

202 A first creep parameter $\mathrm{C}_{\mathrm{IT}}$, e.g. the normalized indentation creep parameter, was 203 calculated by the machine. It is defined as:

$$
C_{I T}(\%)=\frac{h_{\max }-h_{1}}{h_{1}} \times 100
$$

204 With $\mathrm{h}_{1}$ the indentation depth at the beginning of the creep stage.

205 Energetic parameters $\mathrm{n}_{\mathrm{IT}}$ and $\mathrm{W}_{\mathrm{t}}$ were also recorded. $\mathrm{n}_{\mathrm{IT}}$ is the proportion of the elastic 206 response relatively to the total energy $\mathrm{W}_{\mathrm{t}}: \mathrm{n}_{\mathrm{IT}}=\mathrm{W}_{\text {elas }} / \mathrm{W}_{\mathrm{t}}$.

207 More meaningful creep parameters $\mathrm{C}$ and $\tau$ can be extracted from the indentation curves 208 (see Fig 2a)) calculating the creep function $L(t)$ [21]:

$L(t)-L(0)=L(t)-\frac{1}{M}=\frac{2 a_{u} \Delta h(t)}{P_{\max }}$

209 Where $\Delta h(t)$ denotes the indentation depth increase during the constant load phase, $\mathrm{a}_{\mathrm{u}}$ 210 denotes the is the radius of the equivalent projected contact area between the indenter

211 probe and the indented surface at the onset of unloading

212 Assuming a logarithmic fit of the creep function, the creep parameters are defined 213 according to [25]:

$L(t)-\frac{1}{M}=\frac{\ln (t / \tau+1)}{C}$

214 It was verified that this law can adequately reproduce the creep behavior of both cement

215 paste and sand as illustrated in Fig. 2 b). In order to avoid drying during creep

216 experiments, indentation was realized at a relative humidity close to the one imposed

217 during the irradiation period (around 65\% RH). Moreover, autogenous shrinkage of the 
218 sample can be neglected at the age of $72 \mathrm{~d}$. Then, the creep function is expected to

219 characterize the basic creep behavior of the specimens.

220

a)

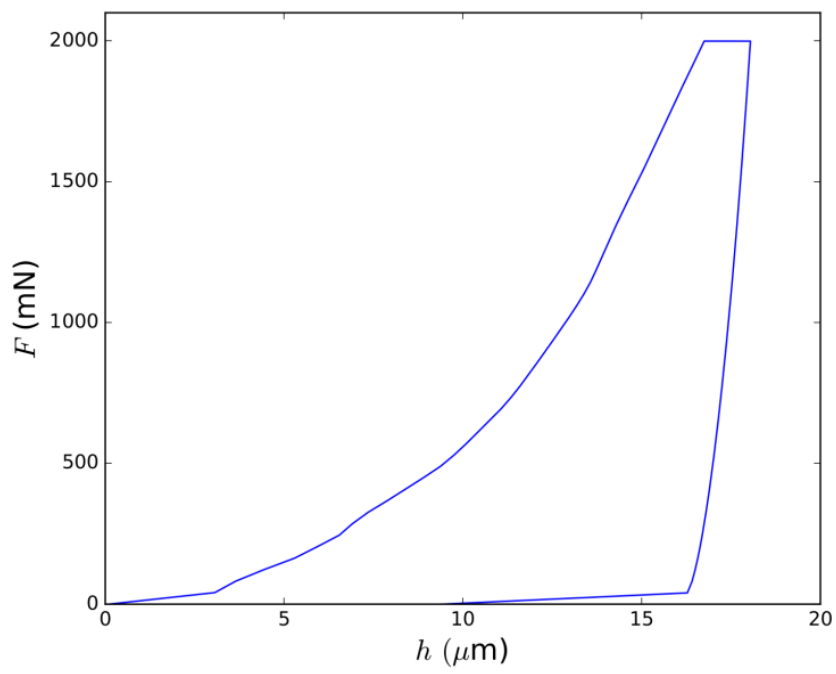

b)

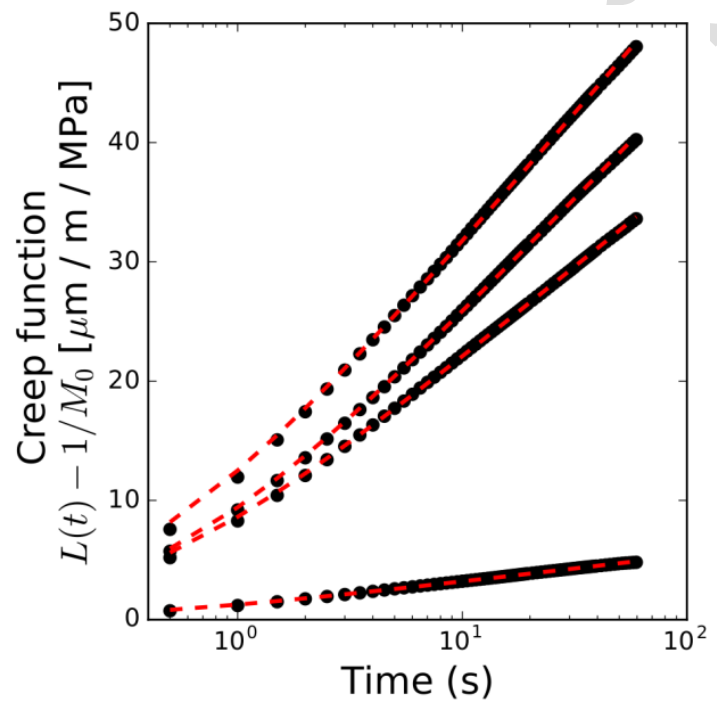

221 Fig. 2. Microindentation outputs: a) raw load - penetration curve, b) fitting the creep 222 function by a logarithmic law (3 curves correspond to cement paste indents and 1 to a 223 sand indent) 


\subsection{D microscope measurements and analysis}

226 After indentation, a map of the indented zone was realized using a Hirox RH-2000 3D

227 microscope by merging around 200 3D reconstructed images evenly spaced along the

228 indented area. The selected magnification (x 140) led to a final horizontal resolution of

229 the 2D projected image of $1.5 \mu \mathrm{m} /$ pix which is adequate to correctly locate the indents

230 and assess their nature. Because some indents may be hardly located, especially the

231 ones created in voids, a basic routine was implemented in Python to locate all the

232 indents based on the location of 3 of them by drawing blue squares on the original

233 image. As illustrated in Fig. 3, the 20 x 20 matrix of indents covers a sufficiently large

234 area representative of the mortar volume and the reconstructed image correctly

235 represent the matrix without image distortion due to multiple image merging (it was

236 verified that the indents were correctly located by the blue squares). The nature of the

237 indents was then manually identified because color-based filters were found to be

238 relatively imprecise in the case of such mortar images.

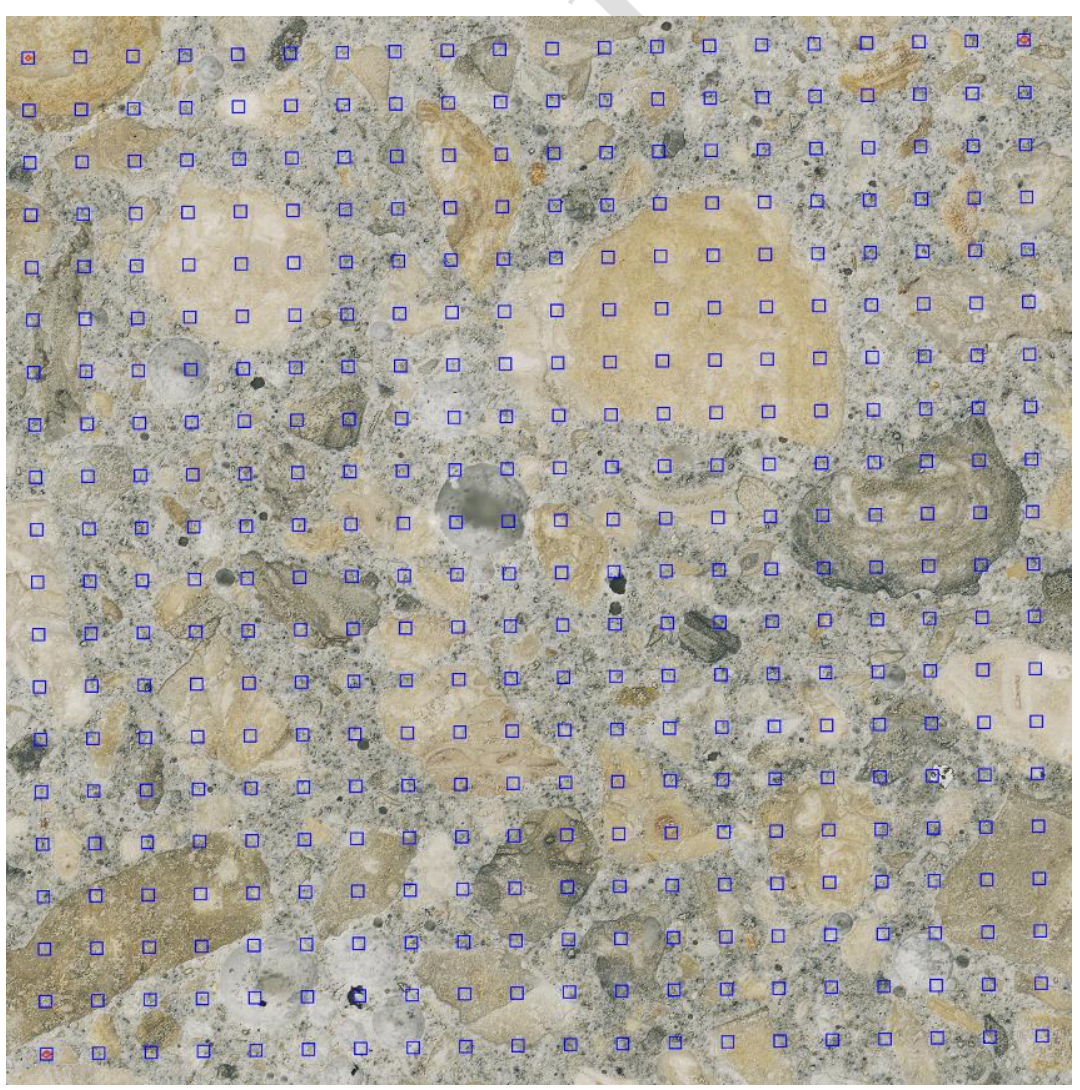


240 Fig. 3. 2D projected global view of the $20 \times 20$ matrix of indents over a $1 \times 1 \mathrm{~cm}^{2}$

241 surface from 3D microscope acquisition (indents are indicated by blue squares)

\section{3. Results and discussion}

\section{3.1 Statistical indentation data deconvolution and its variability}

245 First, indentation outputs from each specimen were visualized by mean of a scatter plot

246 as illustrated in Fig. 4. Several basic observations directly arise from the analysis of the

247 scatter plot. Some data points are isolated from the others. These isolated points are

248 mainly indents with a maximum penetration depth $\mathrm{h}_{\max }$ greater than $20 \mu \mathrm{m}$. In order to

249 properly run data deconvolution, these points were filtered out on all samples. As we

250 will see in the next paragraph, they correspond to indents close to voids or local defects

251 and therefore do not correctly represent cement paste properties. Due to sand

252 heterogeneities, some data points exhibit indentation hardness greater than $2500 \mathrm{MPa}$.

253 Such points were also filtered out of the analysis. Already reported correlations can be

254 highlighted in the scatter plot: correlation between hardness and Young's modulus,

255 linear-shaped correlation between hardness and creep modulus. Looking at the PDFs

256 located along the diagonal of the scatter plots, one may also observe that two main

257 groups, presumably the cement paste and the sand, can be identified (especially on $\mathrm{H}_{\mathrm{IT}}$

258 and $\left.\mathrm{E}_{\mathrm{IT}} \mathrm{PDFs}\right)$. However, these two groups considerably overlap each over, probably

259 due to a non-negligible proportion of the indents at the interface between cement paste

260 and sand grains. 


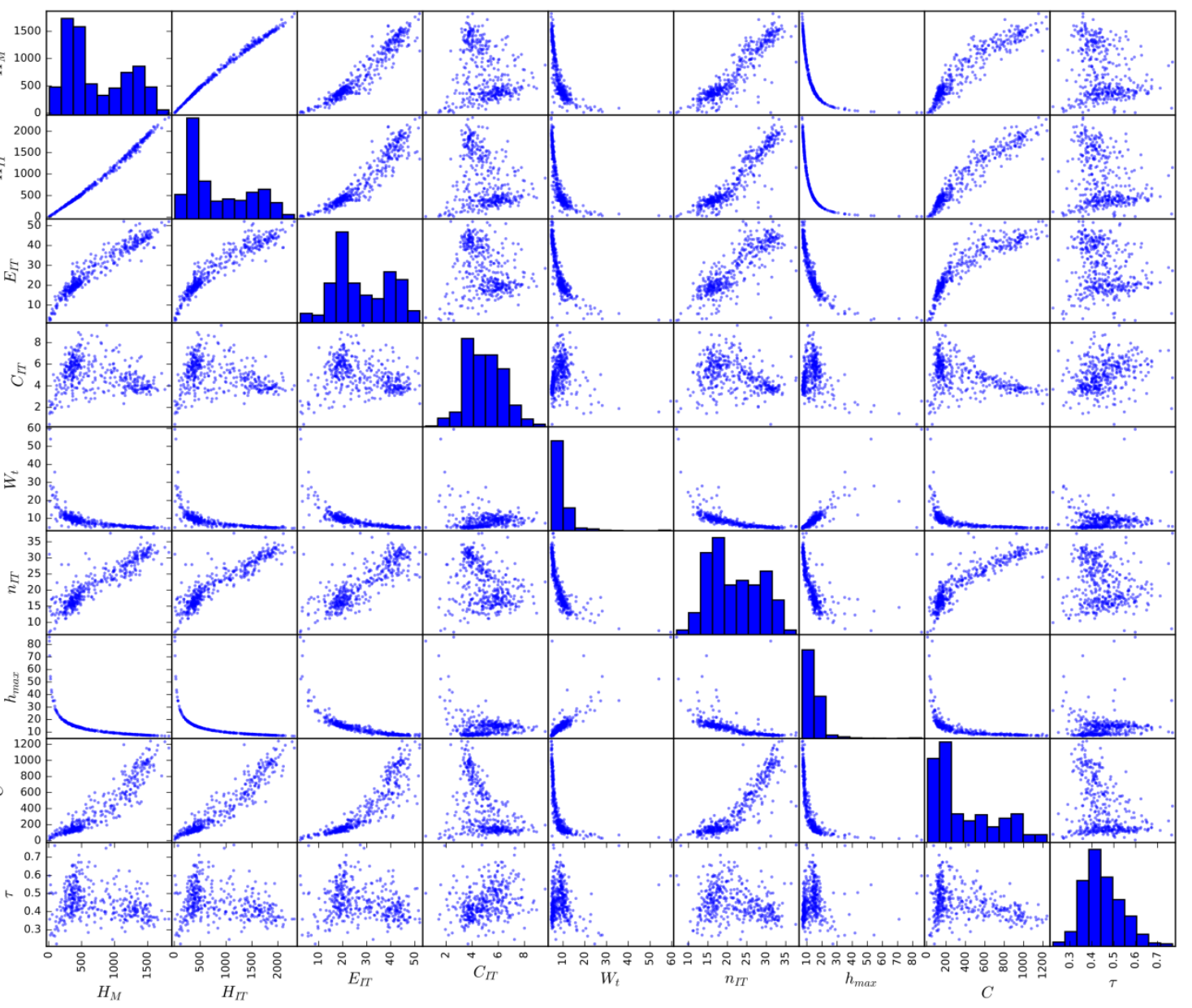

262 Fig. 4. Unfiltered scatter plot from sample MD-257kGy-S3 $\left(\mathrm{H}_{\mathrm{M}}\right.$ and $\mathrm{H}_{\mathrm{IT}}$ are expressed

263 in $\mathrm{MPa}, \mathrm{E}_{\mathrm{IT}}$ and $\mathrm{C}$ in $\mathrm{GPa}, \mathrm{C}_{\mathrm{IT}}$ and $\mathrm{n}_{\mathrm{IT}}$ in $\%, \mathrm{~W}_{\mathrm{t}}$ in $\mu \mathrm{J}, \mathrm{h}_{\max }$ in $\mu \mathrm{m}$ and $\tau$ in $\left.\mathrm{s}\right)$.

264 Then, data points repartition was visualized using a Euclidian distance-based 265 dendrogram generated from the 9 output variables as illustrated in Fig 5 a). This way, 266 the similarities between the data points can be highlighted without subjectivity 267 (subjectivity may come from the arbitrary choice of the number of clusters prior to 268 deconvolution, the output variables used to generate the clusters, e.g. typically 2 [9] or 3 269 [14] only). The data points mainly belong to two dissimilar groups joining at a high 270 around 60 and with their subgroups differentiated at highs around 20.

271 Cutting the dendrogram at a high of 30 leads to a 2-groups hierarchical clustering 272 represented on a C-H $\mathrm{H}_{\mathrm{IT}} 2 \mathrm{D}$ plane (Fig. 5 b)) with one group probably mainly composed 273 of cement paste and one group probably mainly composed of sand. Cutting the 
274 dendrogram at a high of 20 leads to 3 groups (Fig. 5 c)). Naturally, because of 275 hierarchical clustering principles, only one of the two groups has been divided into two 276 subgroups, and for most of the mortar samples it is the group with the highest hardness 277 (presumably sand indents). Then, it means that, at the selected indentation load, sand 278 grains are more heterogeneous than the cement paste. It also leads to another 279 observation: 2-groups (and 3-groups) hierarchical clustering clearly overestimates 280 cement paste proportion, if one basically assumes that the group with the smallest mean 281 hardness corresponds to the cement paste. Indeed, reading the dendrogram, the 282 horizontal proportion of the first group corresponding to the lowest hardness is greater 283 than the one of the second group corresponding to the highest hardness. As the 284 horizontal axis is composed of all the single data points, it would mean that the number 285 of indents in the cement paste is greater than the number of indents in the sand. That is a biased conclusion because the paste volume fraction is only of $45 \%$ (and at this

287 indentation load, an important number of indents are located at the interface between 288 cement paste and sand grains and they would lead to intermediate properties). This 289 erroneous prediction of the phase volume fractions has already been reported elsewhere 290 and the assignation of mean phases properties based on numerical data deconvolution is 291 questionable [15]. This basic observation motivates the use of optical techniques 292 described hereafter to filter experimental data based on indents nature.

293 Reporting the nature of the indents predicted by deconvolution over the microscopic 294 image as illustrated in Fig. 6, a relatively good correspondence is noticeable: red 295 squares corresponding to the first deconvoluted group are mainly located in the paste 296 and blue ones, corresponding to the second group are mainly located in sand grains, 297 while black squares, corresponding to initially filtered values are all near voids. 298 However, some indents (2 of them were circled in orange as examples) numerically 
299 identified as cement paste are located on sand grains and vice versa which emphasizes

300 the limits of numerical clustering.

a)

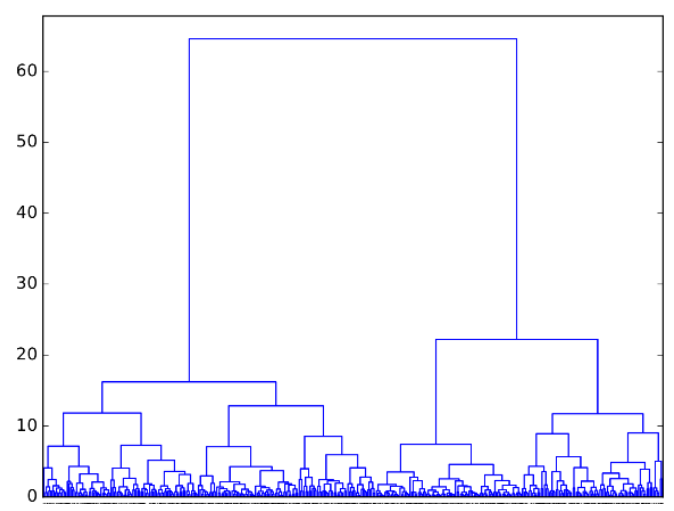

b)

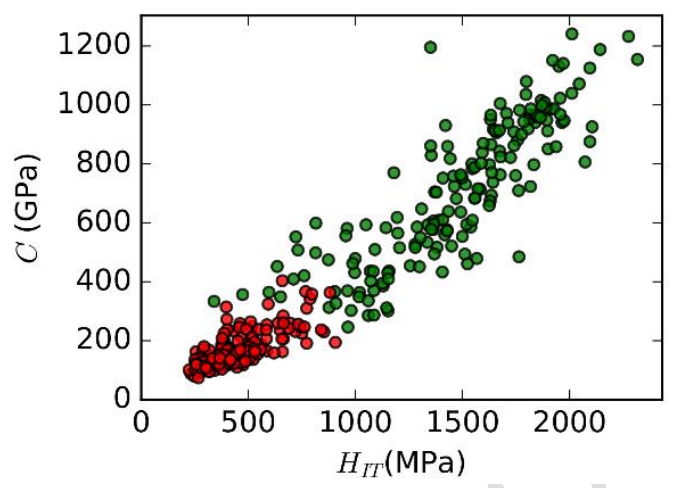

c)

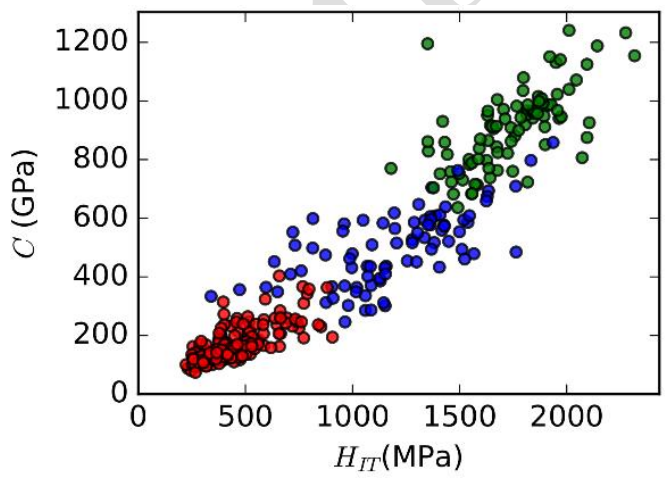

301 Fig. 5. Hierarchical clustering strategy applied to specimen MD-257kGy-S3: a)

302 Euclidian distance-based dendrogram (with the 400 individual data points on the x-

303 axis), b) and c), data points repartition along $\mathrm{C}-\mathrm{H}_{\mathrm{IT}}$ plane using a 2-groups separation

304 (b) and a 3-groups separation (c). 


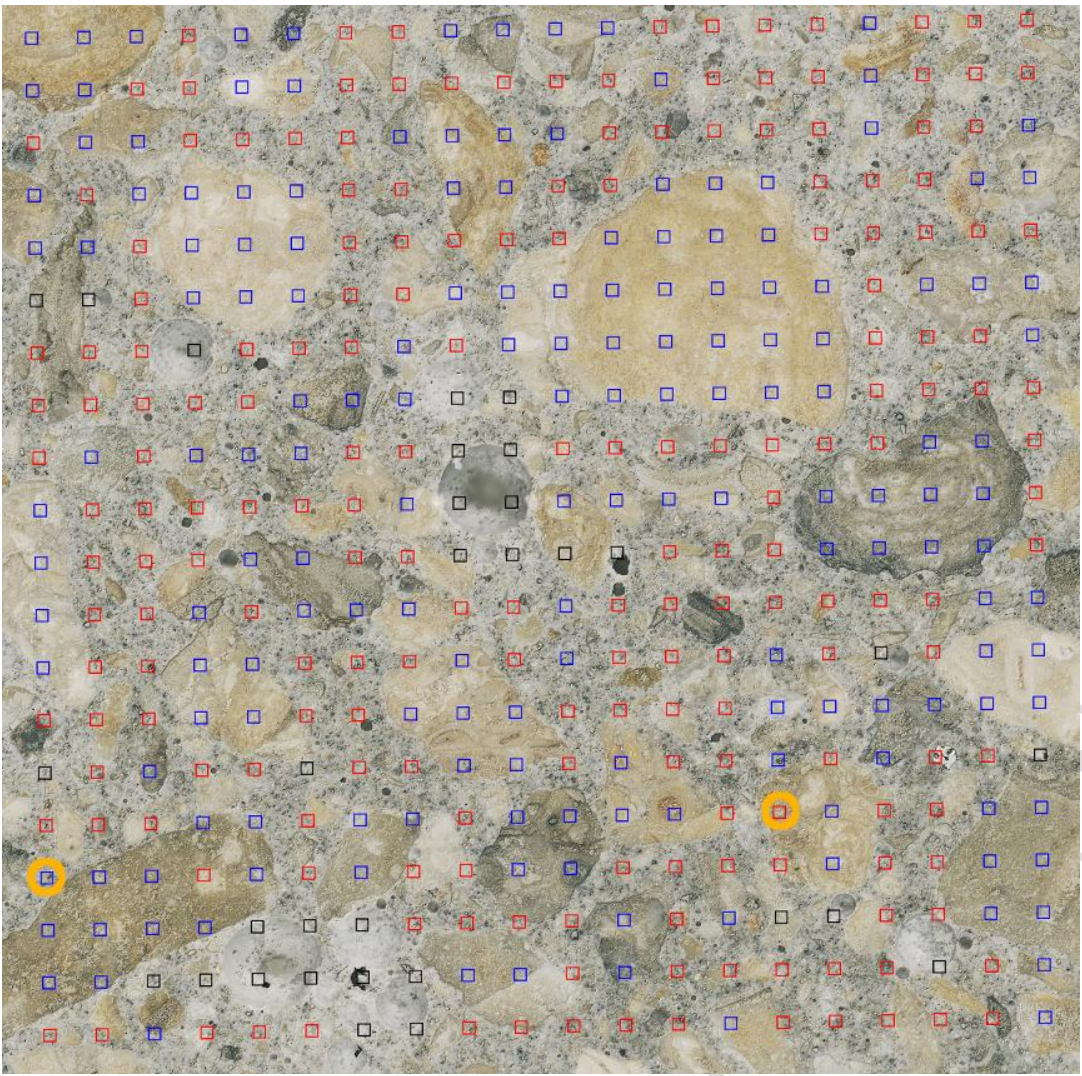

307 Fig. 6. Representation on the 3D microscopic image of specimen MD-257kGy-S3 of the

308 nature of the indents predicted by data deconvolution (red squares correspond to group

309 1, e.g. 'paste', blue squares to group 2, e.g. 'sand, and black squares to filtered values

310 before the analysis). Orange circles indicate two indents attributed to the wrong group

311 as an example of the limits of numerical clustering. Indentation area extends over

$3121 \times 1 \mathrm{~cm}^{2}$.

313

\section{$314 \quad 3.23 D$ microscope results}

315 Indents were visually classified into 4 groups: voids, paste, sand and interface between

316 paste and sand so that the latter 3 could be compared to the 3 groups obtained by

317 hierarchical clustering. As illustrated in Fig. 7, there is an important proportion of

318 indents located at the cement paste - sand grains interface marked by green squares.

319 This is directly correlated to the indent size relatively to the size of the phase and the 
320 volume fraction of sand. Comparing Fig. 6 with Fig. 7, one may notes that the other

321 indents are on majority of the same nature as the indents attributed to one group using

322 the hierarchical clustering method.

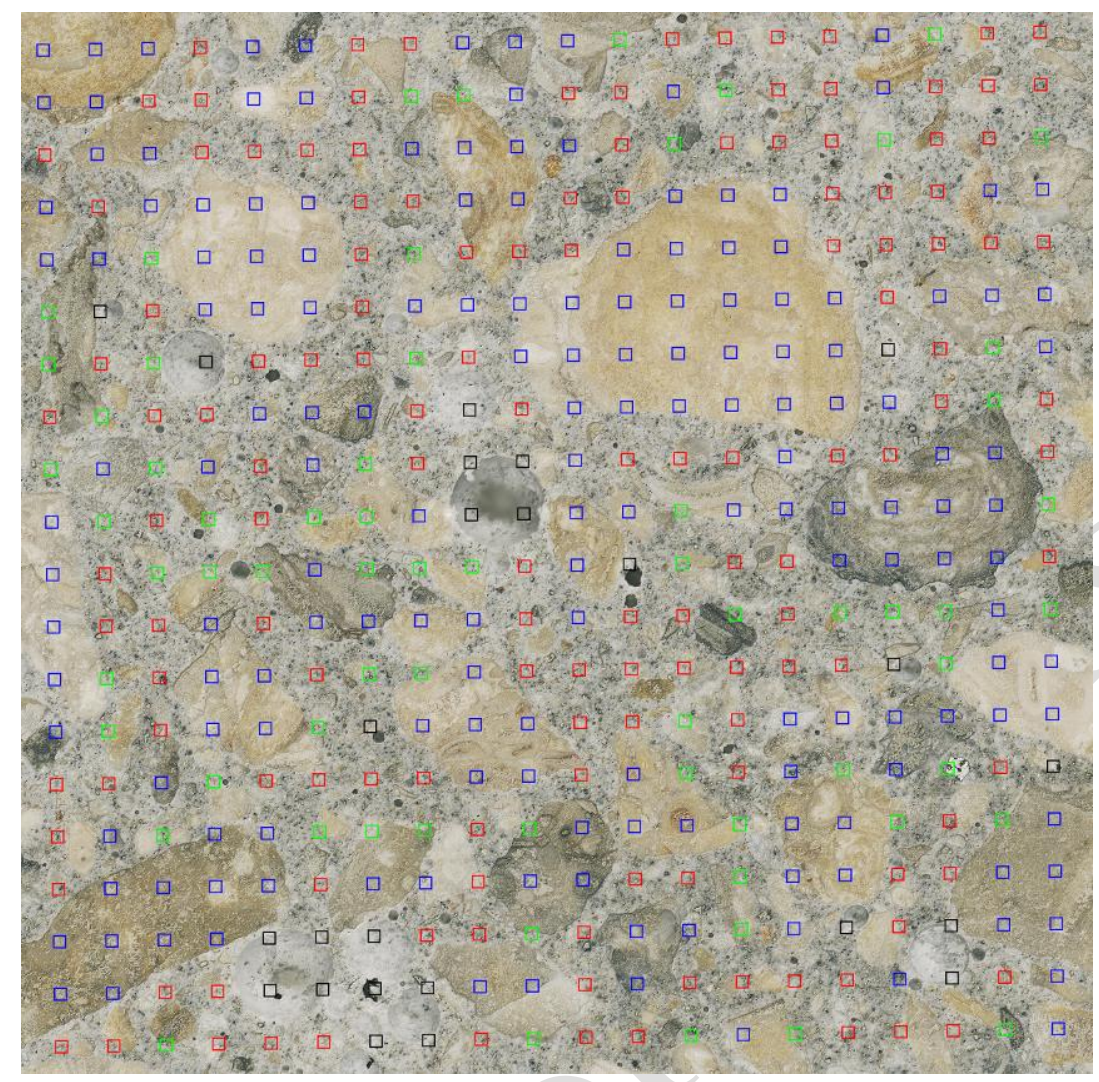

324 Fig. 7. Indents location and nature of specimen MD-257kGy-S3 (paste in red, cement

325 paste - sand grain interface in green, pure sand in blue, void in black) according the 3D

326 microscope image analysis.

328 From the repartition of the indented outputs variables per groups using 3D microscope

329 (Fig. 8), it can be observed that cement paste and sand indentation variables

330 distributions closely match normal distributions. On the other side, properties associated

331 with indents located at interfaces between cement paste and sand grains (green

332 histograms) are much more variables and do not follow any specific distribution. This is

333 due to the fact that indents on interfaces could either exhibit the mean value when two

334 phases properties are probed (for example there are a lot of indents on interfaces with 
335 Young's modulus between 25 and $35 \mathrm{GPa}$, because this property is representative of a

336 large volume), either be very similar to cement paste or sand properties because the

337 indenter probe slide to one side during loading (most of the time, to the cement paste

338 side because of its lower altitude). For this reason, a lot of indents on interfaces have an

339 indentation hardness around $500 \mathrm{MPa}$, e.g. around the mean value of indents attributed

340 to the cement paste as this property is representative of a smaller volume.

341 Identifying phases properties based on imaging is therefore possible for predominant

342 phases like cement paste or sand. Distributions are well defined but some indents

343 properties are possibly associated with the wrong group. For example, in Fig. 8, one can

344 see that some indents with high hardness and creep modulus (around $1 \mathrm{GPa}$ and

$345400 \mathrm{GPa}$ resp.) were identified as cement paste while some indents with Young's

346 modulus lower than $15 \mathrm{GPa}$ were identified as sand grains. More than half of these

347 values are associated with either an odd indent shape on sand or the presence of very

348 small sand grains close to an indent attributed to the cement paste (most of these indents

349 are probably rightly on cement paste but the indentation variables may be influence by

350 very close sand grains even under the indent). Thus, although the optical identification

351 of the indents should be attractive and sufficient in some cases, the combination of a

352 numerical deconvolution technique and of an imaging technique may help reduce the

353 uncertainties concerning some minor odd indents outputs. 

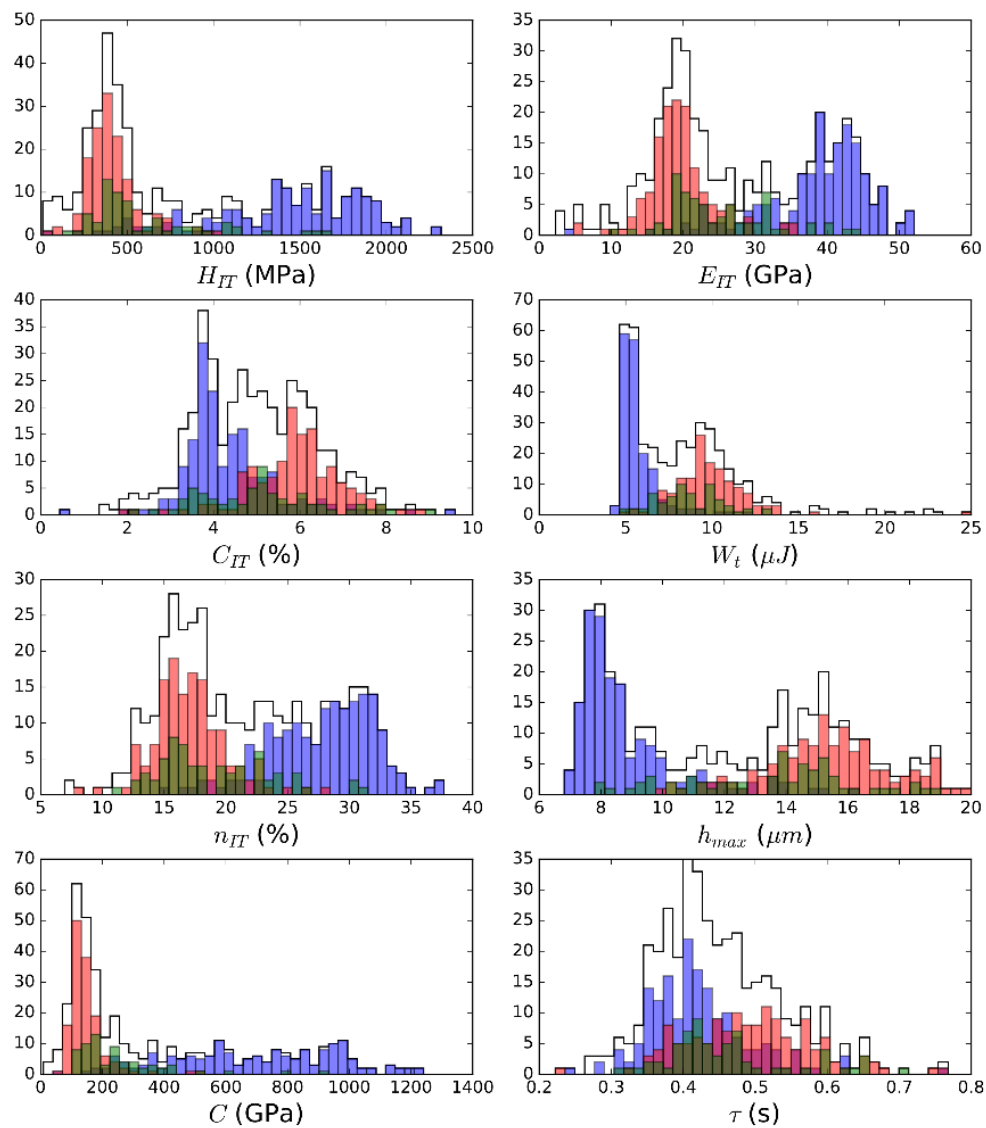

Fig. 8. Histograms of distributions of the indentation output variables of specimen MD$257 \mathrm{kGy}-\mathrm{S} 3$. Total distribution is represented by the continuous black line, distributions

357 of the phases identified using the 3D microscope are colored in red (cement paste), blue 358 (sand grains) and green (cement paste - sand grain interface).

\subsection{Combination of 3D microscope and indentation results}

$3613 \mathrm{D}$ microscope and indentation data deconvolution phase assignations were combined

362 to reduce the variability of the identified phase properties. Comparing the indent natures

363 from the two first order techniques (3D microscope 3 groups identification vs 3 groups

364 hierarchical clustering), the indents with corresponding natures were considered as

365 representative of a given phase while the others were considered as non-reliable

366 information regarding the final application of this study, e.g. cement paste

367 characterization. This coupling may address the two main preoccupations of the first 
order analysis: concerning numerical clustering this method can effectively provide a

369 supplementary information about the nature of the indents and, concerning optical

370 clustering, the method can considerably decrease the risk of false identification (either

371 due to the operator or to the image precision) by selecting clusters of indents with close

372 micromechanical properties.

373 From a visual inspection of the spatial repartition of the nature of the indents in one of

374 the worst cases (Fig. 9), it should be observed that there is a huge proportion of 375 noncorresponding indent natures (yellow squares). Indeed, when comparing 3 groups

376 from 3D microscope identification and 3 groups from data deconvolution, around 35\%

377 of indents nature do not correspond between the two analysis, while this proportion is

378 usually around $25 \%$ for the comparison between 3 groups from 3D microscope and 2

379 groups from data deconvolution. A majority of noncorresponding indents are located in

380 sand grains or at their periphery and this is the reason explaining why there is less error

381 using 2 groups data from deconvolution data: data points numerically identified as

382 belonging to the intermediate group were mostly visually identified as sand grains and

383 not sand grain - cement paste interface. Only a very few indents were identified as

384 interfaces by combining the two methods which means that groups identified by

385 clustering algorithms with intermediate properties are not necessarily different phases

386 (here sand grain - cement paste interface). Moreover, the variability of sand grain

387 properties could also be visualized as for some sand grains almost all indents are

388 corresponding ones, while for others, probably with smaller hardness, indents are

389 mostly noncorresponding ones (identified as sand for one analysis, interface for the 390 other). 


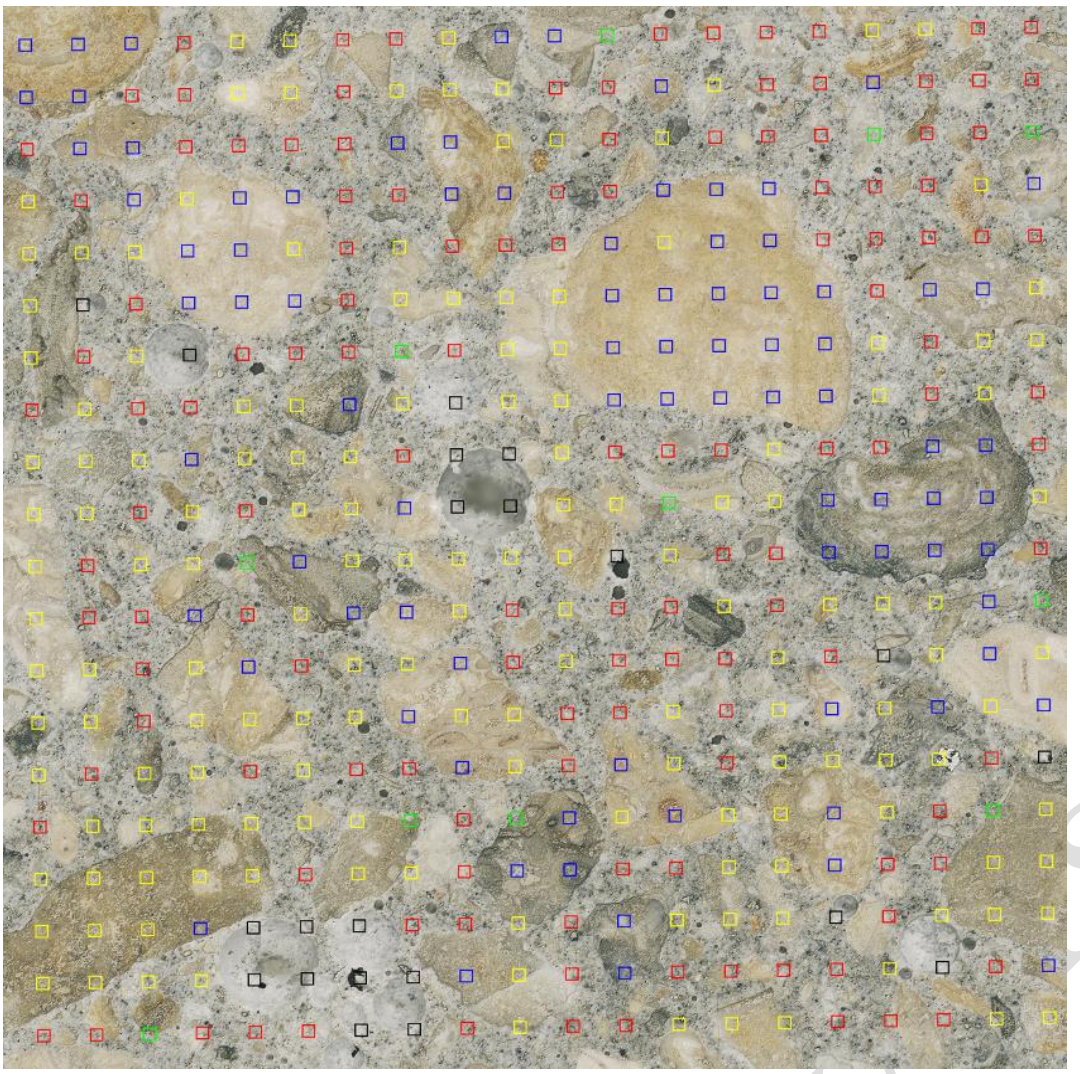

392 Fig. 9. Indents location and nature of specimen MD-257kGy-S3 comparing 3D

393 microscope image analysis and 3 groups hierarchical data deconvolution (paste in red,

394 cement paste - sand grain interface in green, pure sand in blue, void in black and indents

395 with noncorresponding natures between the two analyses in yellow).

397 A detailed analysis of the microindentation output variables through histograms (Fig.

398 10) reveals that noncorresponding indents are mainly the ones with intermediate 399 properties as predicted by the visual observation. Interestingly, the initial goal of this

400 comparison method seems to have been achieved: cement paste and sand distributions 401 are tightened and do not overlap for Young's modulus, hardness and creep modulus.

402 Moreover, some of the extreme values are filtered out. Thus, the comparison of 403 numerical data deconvolution and optical data clustering efficiently reduces the 404 uncertainties concerning phase identification because of the complementarity between 405 the two methods. 

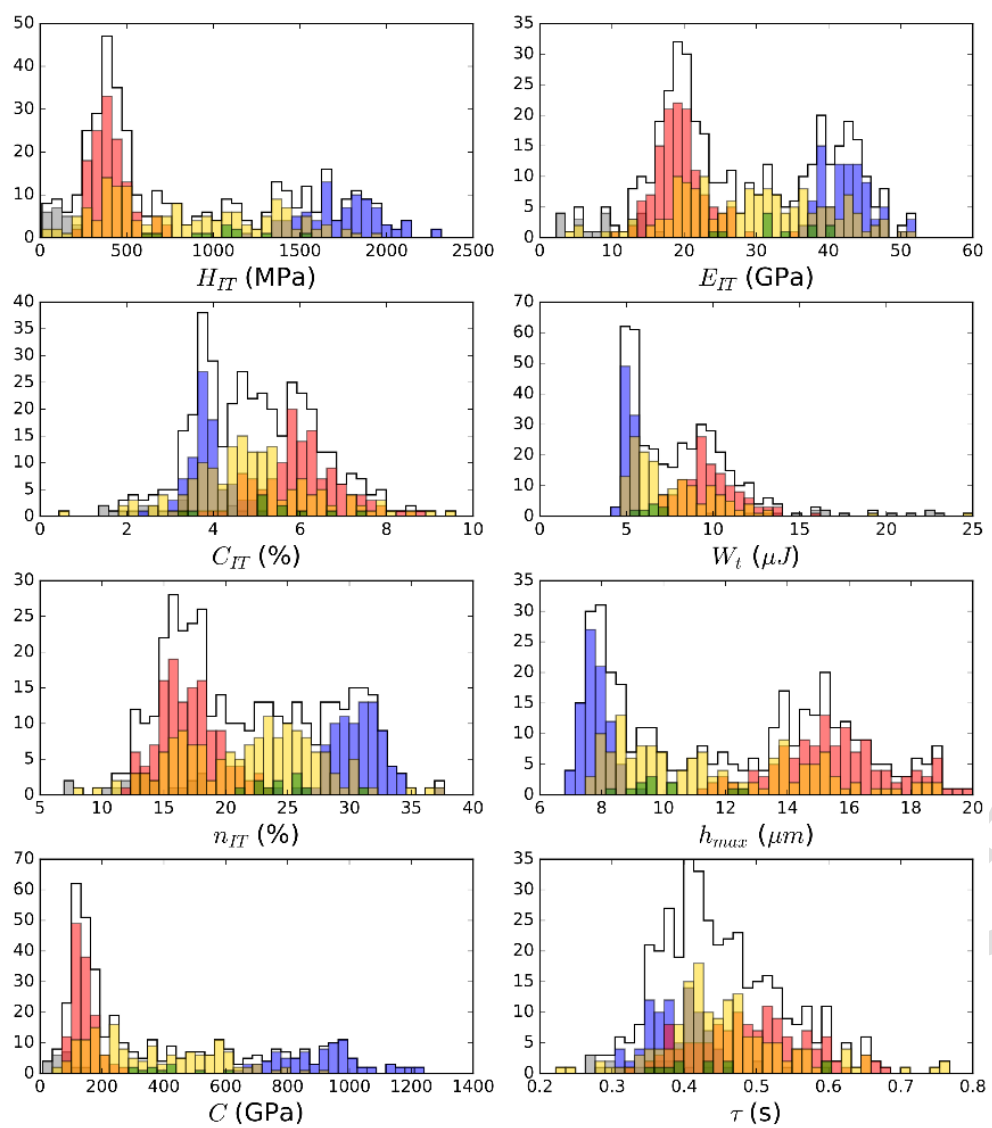

408 Fig. 10. Histograms of distributions of the indentation output variables of specimen MD-257kGy-S3 after the combined use of numerical and clustering and image analysis.

410 Total distribution is represented by the continuous black line, distributions of the phases

411 are colored in red (cement paste), blue (sand grains), green (sand grain - cement pastes

412 interface). The distribution of noncorresponding indents is represented in yellow.

\section{$414 \quad 3.4$ Creep properties of $\boldsymbol{\gamma}$-irradiated mortar specimens}

415 Using the method described in the previous paragraphs, cement paste properties of

416 irradiated and control mortar specimens were compared. Tables 2 to 4 summarize the

417 indentation outputs associated with hierarchical clustering, 3D-microscope image 418 analysis and the method coupling numerical indentation data clustering and 3D-

419 microscope image analysis. As explained, the main interest of the technique is to reduce 
420 the variability of the indentation outputs attributed to one phase, here the cement paste.

421 This objective is achieved for most of the outputs as the variances of the outputs 422 variables distributions in Table 4 are smaller than the corresponding ones on Table 2

423 and 3 both on individual specimens and on the two series merging data from the 3

424 specimens per series. Moreover, mean values of hardness, Young's modulus, creep

425 parameter are smaller on Table 4 because some data points with intermediate properties

426 were filtered out comparing numerical clustering and optical clustering.

427 One may finally observe that it is rather difficult to draw some conclusions on the

428 evolution of the output variables due to irradiations from these data as the standard error

429 (square-root of the variance) is close or greater than the difference between the two

430 series. Thus, indentation outputs were grouped together whether they belong to

431 irradiated specimens or not. The merged data is represented on Fig. 11. Analyzing non-

432 diagonal graphics, one may observe that data points are rather well concentrated and

433 dispersion limited. On diagonal probability distributions (PDF), a clear shift of C due to

434 irradiations can be observed towards greater values while $\tau$ decreases. Indentation

435 hardness also seems to be affected, though statistical analysis is necessary to conclude 436 concerning a possible influence of irradiations.

437 
438 Table 2. Indentation outputs for cement paste indents identified using hierarchical

439 clustering (means and variances in brackets).

\begin{tabular}{cccccccccc} 
& $\mathrm{HM}(\mathrm{MPa})$ & $\mathrm{HIT}(\mathrm{MPa})$ & $\mathrm{EIT}(\mathrm{GPa})$ & $\mathrm{CIT}(\%)$ & $\mathrm{Wt}(\mu \mathrm{J})$ & $\mathrm{nIT}(\%)$ & $\mathrm{hmax}(\mu \mathrm{m})$ & $\mathrm{C}(\mathrm{GPa})$ & $\tau(\mathrm{s})$ \\
\hline \hline \multirow{2}{*}{ MD-257kGy-I1 } & 377.4 & 402.7 & 19.5 & 5.16 & 10.2 & 16.7 & 15.40 & 173 & 0.384 \\
& $(5424)$ & $(6192)$ & $(5.2)$ & $(1.22)$ & $(2.0)$ & $(4.2)$ & $(2.30)$ & $(1111)$ & $(0.005)$ \\
\hline \multirow{2}{*}{ MD-257kGy-I2 } & 432.0 & 466.6 & 21.0 & 5.20 & 9.3 & 18.1 & 14.54 & 197 & 0.416 \\
& $(13035)$ & $(16610)$ & $(15.5)$ & $(1.51)$ & $(2.8)$ & $(8.1)$ & $(3.30)$ & $(3534)$ & $(0.007)$ \\
\hline \multirow{2}{*}{ MD-257kGy-I3 } & 438.8 & 478.8 & 21.3 & 5.04 & 9.2 & 19.0 & 14.46 & 210 & 0.447 \\
& $(16321)$ & $(22917)$ & $(28.2)$ & $(1.02)$ & $(2.8)$ & $(14.9)$ & $(3.92)$ & $(8623)$ & $(0.005)$ \\
\hline \multirow{2}{*}{ MD-257kGy-S1 } & 396.9 & 415.4 & 20.2 & 6.00 & 10.1 & 16.7 & 15.26 & 149 & 0.465 \\
& $(9088)$ & $(10205)$ & $(8.4)$ & $(1.29)$ & $(2.4)$ & $(6.2)$ & $(3.13)$ & $(1006)$ & $(0.005)$ \\
\hline \multirow{2}{*}{ MD-257kGy-S2 } & 369.3 & 395.2 & 19.9 & 4.99 & 9.7 & 17.5 & 15.58 & 182 & 0.426 \\
& $(6869)$ & $(8737)$ & $(12.5)$ & $(1.89)$ & $(3.0)$ & $(10.5)$ & $(2.79)$ & $(4653)$ & $(0.006)$ \\
\hline \multirow{2}{*}{ MD-257kGy-S3 } & 416.1 & 441.0 & 20.8 & 5.77 & 9.7 & 17.3 & 15.01 & 165 & 0.481 \\
& $(16467)$ & $(20063)$ & $(18.1)$ & $(1.43)$ & $(3.2)$ & $(7.4)$ & $(4.34)$ & $(3481)$ & $(0.007)$ \\
\hline \hline \multirow{2}{*}{ MD-257kGy-I } & 421.8 & 456.2 & 20.7 & 5.13 & 9.5 & 18.1 & 14.71 & 196 & 0.420 \\
& $(13019)$ & $(17314)$ & $(18.2)$ & $(1.27)$ & $(2.7)$ & $(10.4)$ & $(3.43)$ & $(4998)$ & $(0.006)$ \\
\hline \multirow{2}{*}{ MD-257kGy-S } & 396.2 & 420.2 & 20.4 & 5.55 & 9.8 & 17.2 & 15.25 & 168 & 0.459 \\
& $(12102)$ & $(14600)$ & $(14.4)$ & $(1.73)$ & $(3.0)$ & $(8.3)$ & $(3.62)$ & $(3539)$ & $(0.007)$ \\
\hline
\end{tabular}

440

441 Table 3. Indentation outputs for cement paste indents identified using 3D-microscope

442 image analysis (means and variances in brackets).

\begin{tabular}{cccccccccc} 
& HM $(\mathrm{MPa})$ & HIT $(\mathrm{MPa})$ & $\mathrm{EIT}(\mathrm{GPa})$ & $\mathrm{CIT}(\%)$ & $\mathrm{Wt}(\mu \mathrm{J})$ & $\mathrm{nIT}(\%)$ & $\mathrm{hmax}(\mu \mathrm{m})$ & $\mathrm{C}(\mathrm{GPa})$ & $\tau(\mathrm{s})$ \\
\hline \hline \multirow{2}{*}{ MD-257kGy-I1 } & 440.8 & 476.8 & 21.2 & 5.24 & 9.4 & 18.0 & 14.50 & 199 & 0.400 \\
& $(19742)$ & $(27060)$ & $(12.9)$ & $(1.29)$ & $(2.9)$ & $(11.9)$ & $(3.92)$ & $(4667)$ & $(0.005)$ \\
\hline \multirow{2}{*}{ MD-257kGy-I2 } & 434.1 & 468.9 & 20.6 & 5.33 & 9.4 & 17.9 & 14.60 & 192 & 0.425 \\
& $(17383)$ & $(23191)$ & $(16.4)$ & $(1.20)$ & $(3.0)$ & $(8.3)$ & $(3.82)$ & $(4943)$ & $(0.007)$ \\
\hline \multirow{2}{*}{ MD-257kGy-I3 } & 431.9 & 464.6 & 20.4 & 5.63 & 9.3 & 18.6 & 14.64 & 177 & 0.478 \\
& $(15769)$ & $(21090)$ & $(20.5)$ & $(1.15)$ & $(2.2)$ & $(12.4)$ & $(3.50)$ & $(4922)$ & $(0.007)$ \\
\hline \multirow{2}{*}{ MD-257kGy-S1 } & 480.2 & 509.0 & 22.4 & 6.39 & 9.1 & 18.1 & 14.01 & 166 & 0.558 \\
& $(22752)$ & $(32818)$ & $(15.9)$ & $(0.97)$ & $(2.3)$ & $(10.6)$ & $(3.09)$ & $(5071)$ & $(0.013)$ \\
\hline \multirow{2}{*}{ MD-257kGy-S2 } & 412.5 & 443.9 & 20.3 & 5.44 & 9.6 & 17.6 & 15.17 & 180 & 0.435 \\
& $(28845)$ & $(42071)$ & $(18.6)$ & $(1.62)$ & $(2.8)$ & $(9.7)$ & $(4.73)$ & $(8569)$ & $(0.005)$ \\
\hline \multirow{2}{*}{ MD-257kGy-S3 } & 402.8 & 425.0 & 20.0 & 6.00 & 9.7 & 17.3 & 15.29 & 151 & 0.495 \\
& $(16326)$ & $(20613)$ & $(18.6)$ & $(0.96)$ & $(3.2)$ & $(8.1)$ & $(4.33)$ & $(3661)$ & $(0.007)$ \\
\hline \hline \multirow{2}{*}{ MD-257kGy-I } & 435.7 & 470.2 & 20.8 & 5.40 & 9.4 & 18.2 & 14.58 & 190 & 0.434 \\
& $(17592)$ & $(23734)$ & $(16.5)$ & $(1.24)$ & $(2.7)$ & $(10.9)$ & $(3.74)$ & $(4898)$ & $(0.007)$ \\
\hline \multirow{2}{*}{ MD-257kGy-S } & 432.2 & 459.5 & 20.9 & 5.95 & 9.5 & 17.7 & 14.82 & 165 & 0.497 \\
& $(23588)$ & $(32752)$ & $(18.8)$ & $(1.32)$ & $(2.8)$ & $(9.6)$ & $(4.36)$ & $(5814)$ & $(0.011)$ \\
\hline
\end{tabular}


444 Table 4. Indentation outputs for cement paste indents identified using the proposed

445 method coupling numerical clustering and image analysis (means and variances in 446 brackets).

\begin{tabular}{cccccccccc} 
& HM (MPa) & HIT $(\mathrm{MPa})$ & $\mathrm{EIT}(\mathrm{GPa})$ & $\mathrm{CIT}(\%)$ & $\mathrm{Wt}(\mu \mathrm{J})$ & $\mathrm{nIT}(\%)$ & hmax $(\mu \mathrm{m})$ & $\mathrm{C}(\mathrm{GPa})$ & $\tau(\mathrm{s})$ \\
\hline \hline \multirow{2}{*}{ MD-257kGy-I1 } & 376.0 & 400.6 & 19.4 & 5.25 & 10.2 & 16.6 & 15.44 & 168 & 0.391 \\
& $(5267)$ & $(5997)$ & $(4.8)$ & $(1.21)$ & $(2.1)$ & $(4.6)$ & $(2.26)$ & $(919)$ & $(0.004)$ \\
\hline \multirow{2}{*}{ MD-257kGy-I2 } & 416.9 & 448.1 & 20.2 & 5.33 & 9.6 & 17.6 & 14.79 & 183 & 0.429 \\
& $(11407)$ & $(14084)$ & $(12.8)$ & $(1.22)$ & $(2.8)$ & $(6.6)$ & $(3.20)$ & $(2896)$ & $(0.007)$ \\
\hline \multirow{2}{*}{ MD-257kGy-I3 } & 397.8 & 428.1 & 19.7 & 5.35 & 9.6 & 18.1 & 15.09 & 174 & 0.454 \\
& $(8279)$ & $(11073)$ & $(19.3)$ & $(0.91)$ & $(2.1)$ & $(12.2)$ & $(2.79)$ & $(4012)$ & $(0.004)$ \\
\hline \multirow{2}{*}{ MD-257kGy-S1 } & 411.2 & 428.4 & 20.4 & 6.33 & 10.2 & 16.4 & 15.00 & 144 & 0.476 \\
& $(8037)$ & $(9145)$ & $(7.9)$ & $(0.77)$ & $(2.4)$ & $(4.8)$ & $(2.59)$ & $(773)$ & $(0.004)$ \\
\hline \multirow{2}{*}{ MD-257kGy-S2 } & 372.3 & 395.0 & 19.6 & 5.40 & 9.9 & 16.9 & 15.63 & 162 & 0.439 \\
& $(9381)$ & $(11590)$ & $(13.0)$ & $(1.63)$ & $(2.5)$ & $(5.5)$ & $(2.92)$ & $(2310)$ & $(0.005)$ \\
\hline \multirow{2}{*}{ MD-257kGy-S3 } & 387.5 & 406.7 & 19.5 & 6.03 & 9.9 & 17.0 & 15.48 & 142 & 0.493 \\
& $(10432)$ & $(12111)$ & $(12.7)$ & $(0.88)$ & $(2.7)$ & $(5.8)$ & $(3.54)$ & $(1247)$ & $(0.006)$ \\
\hline \hline \multirow{2}{*}{ MD-257kGy-I } & 399.7 & 428.8 & 19.8 & 5.32 & 9.7 & 17.5 & 15.06 & 176 & 0.427 \\
& $(8965)$ & $(11226)$ & $(12.7)$ & $(1.12)$ & $(2.5)$ & $(8.1)$ & $(2.87)$ & $(2723)$ & $(0.006)$ \\
\hline \multirow{2}{*}{ MD-257kGy-S } & 386.0 & 406.1 & 19.7 & 5.85 & 9.9 & 16.9 & 15.45 & 150 & 0.470 \\
& $(9739)$ & $(11455)$ & $(12.0)$ & $(1.26)$ & $(2.6)$ & $(5.5)$ & $(3.17)$ & $(1639)$ & $(0.006)$ \\
\hline
\end{tabular}

447

448 Statistical analysis was performed using Gnumeric software. Because normality of these

449 new distributions could not be guaranteed using normality algorithms and variances

450 could differ slightly, irradiated and control specimens data points were compared using

451 the Welch's t-test (mean comparison assuming normal distributed variables but

452 sufficiently robust to deal with non-normal samples if there are enough data points) and

453 Wilcoxon-Mann-Whitney test (median comparison without normality assumption) as a

454 verification both at a confidence level of 5\%. There is no significant difference

455 concerning Young's moduli in agreement with the tables. After a total irradiated dose of

$456257 \mathrm{kGy}$, there is a significant increase of the creep modulus $\mathrm{C}$ of about $17 \%$ and a

457 significant decrease of indentation characteristic time $\tau$ of about $9 \%$ comparing data

458 points obtained from the method herein presented. Box plots summarizing the results

459 are presented in Fig. 12. These proportions are similar to the ones computed from 
460 hierarchical or 3D-microscope analysis outputs but may not be statistically different in 461 the latter cases, especially when data points are identified using 3D-microscope only.

462 Creep modulus increase is correlated with a slight indentation hardness increase of 463 about $6 \%$ which is significant for data points obtained using the coupled method.

464 Consequently, $\mathrm{h}_{\max }$ slightly decreases while $\mathrm{n}_{\text {IT }}$ slightly increases with irradiations. The 465 indentation energy $\mathrm{W}_{\mathrm{t}}$ remains unchanged proving that only slight changes are 466 occurring.

467
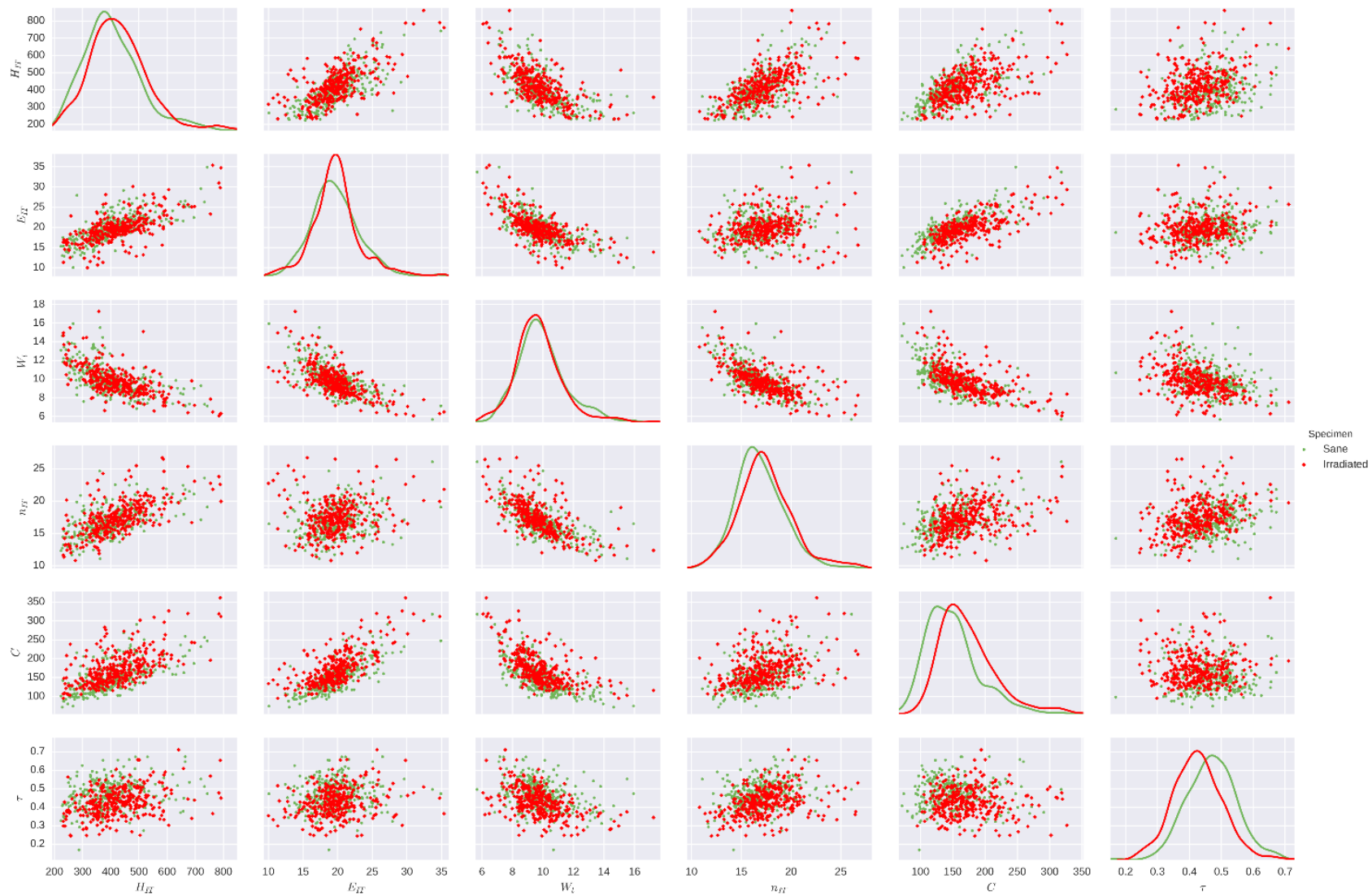

469 Fig. 11. Scatter plot of indentation data points attributed to the cement paste by

470 coupling data deconvolution and image analysis for irradiated and control specimens

$471\left(\mathrm{H}_{\mathrm{IT}}\right.$ is expressed in $\mathrm{MPa}, \mathrm{E}_{\mathrm{IT}}$ and $\mathrm{C}$ in $\mathrm{GPa}, \mathrm{n}_{\mathrm{IT}}$ in $\%, \mathrm{~W}_{\mathrm{t}}$ in $\mu \mathrm{J}$ and $\tau$ in $\left.\mathrm{s}\right)$. 
a)

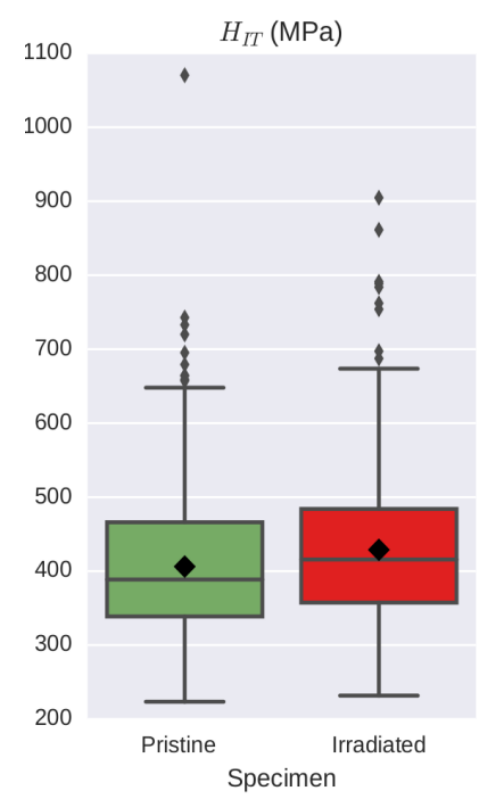

c)

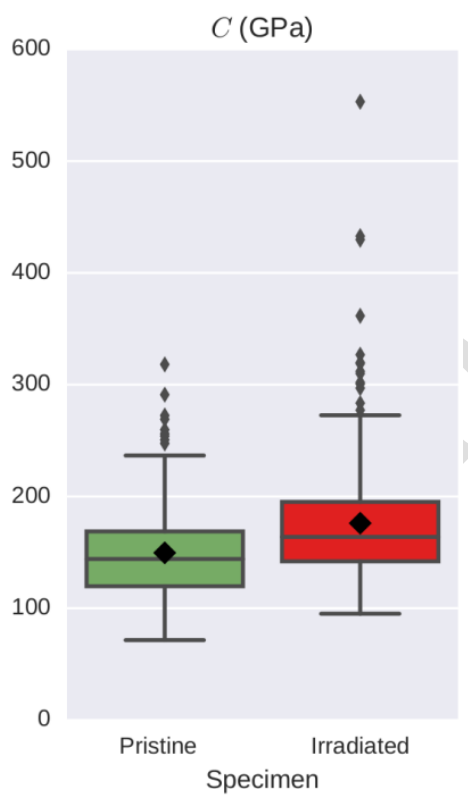

b)

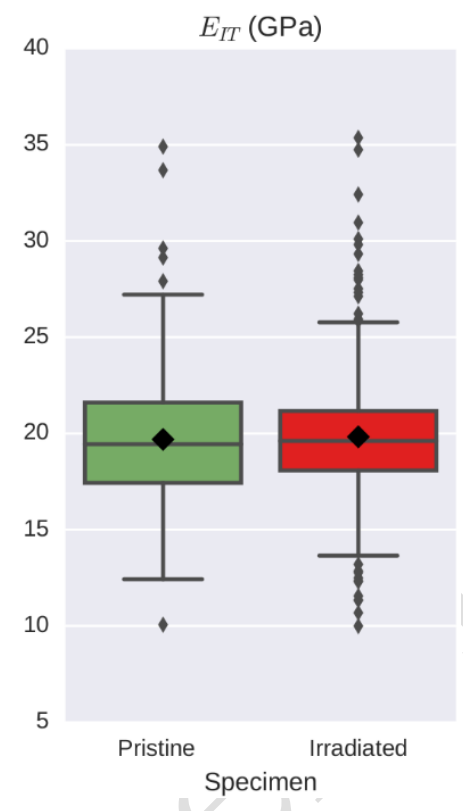

d)

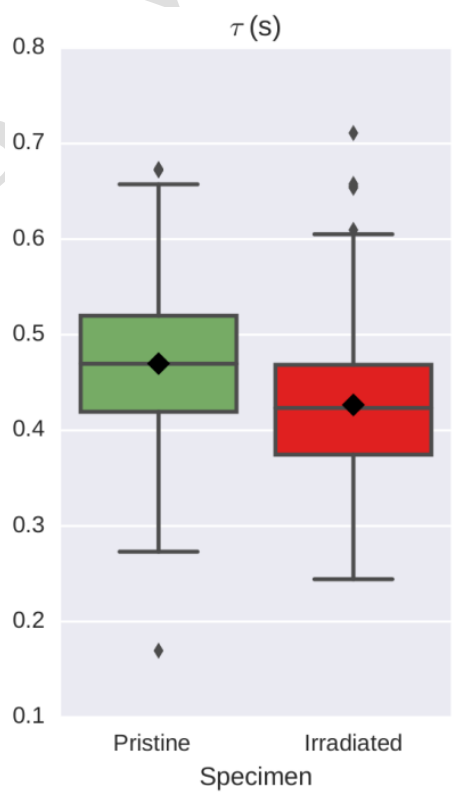

474 Fig. 12. Box plots of indentation data points attributed to the cement paste by coupling 475 data deconvolution and image analysis for irradiated and pristine specimens: a) $\mathrm{H}_{\mathrm{IT}}$, b) $476 \mathrm{E}_{\mathrm{IT}}$, c) $\mathrm{C}$ and d) $\tau$, Center horizontal line of the box represents the median value while 477 thick diamond stands for the mean value. 
479 From our knowledge, these creep results are the first microindentation results 480 concerning irradiated concrete specimens. Therefore, it could be interesting to make a 481 comparison with the only macroscopic creep results under $\gamma$-irradiation reported a long 482 time ago [39] and illustrated as markers in Fig. 13. The experimental macroscopic 483 specific creep function was first fitted using a classic 3-parameters logarithmic law:

$J_{u}(t)-\frac{1}{E_{0}}=\frac{\ln (t / \tau+1)}{C}$

484 This first fit led to an increase of the creep modulus of $74 \%$ (132 GPa for irradiated 485 sample and $76 \mathrm{GPa}$ for control sample) and a decrease of $\tau$ of around $49 \%$ (47 d 486 vs 24d). Tough the raw increases are dramatic and somehow affected by the lack of 487 experimental values compared to the number of parameters, this trend qualitatively 488 agrees with the microindentation results. In order to obtain more realistic creep modulus 489 variations, it has been decided to fit the experimental data using a two parameters law 490 written as:

$J_{u}(t)-\frac{1}{E_{0}}=\frac{\ln (t / c s t e+1)}{C}$

491 Using a characteristic time cste of $25 \mathrm{~d}$ (same order of magnitude as the characteristic 492 time using a 3-parameters fit. but still a relatively small value regarding the dose 493 (around $70 \mathrm{kGy}$ ) at this time), this type of law correctly describe the creep behavior for 494 times greater than $\tau$. As illustrated in Fig. 13, the fit is acceptable for times greater than 495 approximately $40 \mathrm{~d}$. When applied on the regression curves proposed by McDowall, 496 this fit leads to a more reasonable creep modulus increase of 53\% after a total dose $497820 \mathrm{kGy}$ in approximately $300 \mathrm{~d}(141 \mathrm{GPa}$ for the irradiated specimen and $92 \mathrm{GPa}$ for 498 the control specimen). This increase is around three times greater than the increase 499 measured by indentation after a total dose of $257 \mathrm{kGy}$. 

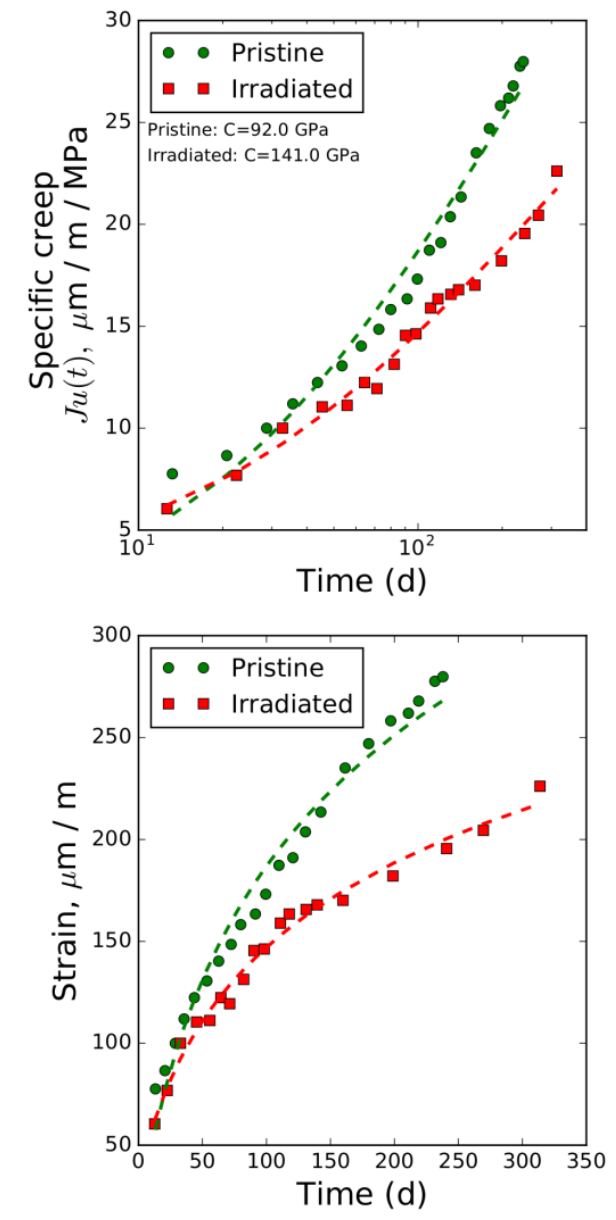

Fig. 13. Comparison between experimental creep results from [39] (markers) and a 2-

502 parameters logarithmic fit (dashed line).

503

504 Therefore, in order to compare creep modulus' increase at similar total doses, we

505 performed 2-parameters fitting up to increasing doses with the assumption that

506 irradiation gradually affects cementitious materials. For this purpose, we approximated

507 the initial fit of the evolution of strain proposed by McDowall in order to feed the

508 algorithm with continuous data. Then logarithmic 2-parameters fitting was realized

509 between dose segments of growing sizes beginning by a first segment of [0 kGy,

$51020 \mathrm{kGy}$ ] and gradually increasing the size of the segment by $0.5 \mathrm{kGy}$. The general trend

511 of the optimization problem for the ratio of the creep modulus evolution assessment,

512 depending on time $\mathrm{t}$ and dose $\mathrm{d}$, is summarized by eq. 12 where $\mathrm{J}$ ' and $\mathrm{J}$ are the specific 
513 creep function of the irradiated and control specimens. The resulting evolution of the

514 ratio between the creep moduli of irradiated concrete specimen and control specimen 515 over the total dose is illustrated in Fig. 14.

516

$$
\frac{C_{\text {Irr }}(d)}{C_{\text {sane }}}=\frac{\min _{C . \tau=25 d} \int_{0}^{d} J_{\text {exp }}^{\prime}(t . d)-J_{\text {num }}^{\prime}(t . d)}{\min _{C . \tau=25 d} \int_{0}^{d} J_{\text {exp }}(t)-J_{\text {num }}(t)}
$$

518 Because the effect of radiations is supposedly small at low doses, creep moduli ratio is 519 close to 1 for small segments and. because the effect of radiation increases with time the 520 ratio gradually increases. It is difficult to say whether the quick increase of the ratio 521 before $50-60 \mathrm{kGy}$ is representative of the concrete behavior or if the fit reliability is 522 affected by the logarithmic function selected (irradiation times are close to the creep 523 characteristic time at low dosage). However, one may observe the ratio exhibits a quasi524 linear increase after $180 \mathrm{kGy}$ (doses at which time $\geq 3 \times$ creep characteristic time). A 525 linear regression with a correlation coefficient of 0.994 is proposed after $180 \mathrm{kGy}$. From 526 this regression, it can be stated that the increase rate is of $5 \times 10^{-2} \% / \mathrm{kGy}$, which leads,

527 considering and initial creep modulus of around $100 \mathrm{GPa}$, to a rate of $50 \mathrm{GPa} / \mathrm{MGy}$. For 528 a dose of $257 \mathrm{kGy}$, the increase of the creep modulus from this method is around $20 \%$ 529 which is in good agreement with the increase calculated from the microindentation 530 experiment. 


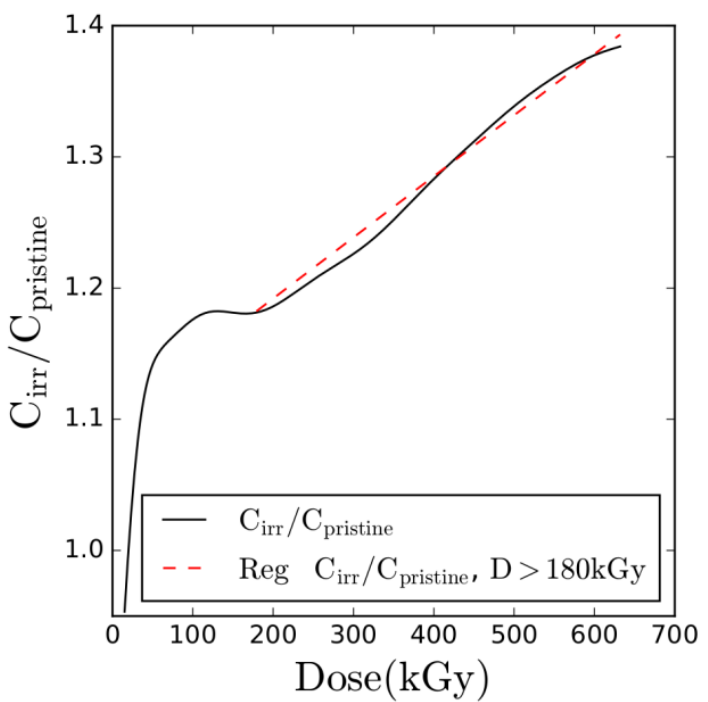

533 Fig. 14. Evolution of the ration between creep moduli calculated for irradiated and

534 control concrete specimens from [39] relatively to the final dose considered for a 2-

535 parameters fitting logarithmic law.

\section{Conclusion and perspectives}

538 In this study, the potential of coupling indentation and optical microscopy for

539 heterogenous materials characterization has been demonstrated. A novel method has

540 been introduced to reduce the variability of the micromechanical properties associated

541 to an indented phase. This method relies on the comparison of the nature of indents

542 numerically predicted by statistical indentation data deconvolution and by 3D-optical

543 microscope image analysis. This method robustly counteracts the uncertainty of

544 numerical clustering methods by introducing optical information. In our study, the data

545 points cluster of interest generated by the method associated with cement paste likely

546 exhibits a normal distribution and a systematic reduced variance compared to each of

547 the technique alone. This herein described method could be applied to a wide range of

548 materials and studies.

549 The proposed method was successfully applied to the assessment of micro-mechanical

550 properties of $\gamma$-irradiated mortar specimens. The method led to the identification of the 
551 cement paste elasto-plastic parameters affected by irradiation at relatively low

552 cumulated dose of $257 \mathrm{kGy}$. It has been found out that creep modulus $\mathrm{C}$ significantly

553 increases by around $17 \%$ and indentation characteristic time $\gamma$ significantly decreases by

554 around $9 \%$ after irradiation. The creep modulus increase is correlated with a slight

555 increase of the indentation hardness $\mathrm{H}_{\text {IT }}$ and of the proportion of the elastic response

556 relatively to the total energy $\mathrm{n}_{\text {IT. }}$ On the other hand, Young's modulus of irradiated

557 specimens does not significantly differ from the one of control specimens.

558 These micro-mechanical observations agree with the only macroscopic uniaxial

559 compressive creep measurements under $\gamma$-irradiation published to our knowledge [39].

560 Using a logarithmic dose-dependant fit of the specific creep function proposed in this

561 study, it can be calculated that the creep modulus increases and the creep characteristic

562 time decreases leading to less creep of the irradiated samples. Then a reverse analysis

563 was proposed to quantify the evolution of the irradiated vs pristine creep moduli ratio

564 with the time increasing $\gamma$-dose. Although supplementary similar experiments should be

565 carried out at both microscale and macroscale with various dose rates, the creep

566 modulus appears to linearly increase with the $\gamma$-dose for doses between 180 and

$567 \quad 700$ kGy.

568

569 Acknowledgments

570 The authors gratefully acknowledge the financial support provided for this study by

571 Tractebel Engineering. Special thanks are due to Xavier Bourbon (ANDRA) for

572 instructive discussions. This work has been supported in part by a grant from the French

573 National Agency for Research called "Investissements d"Avenir". Equipex ArronaxPlus $574 \quad \mathrm{n}^{\circ}$ ANR-11-EQPX-0004. 


\section{References}

577 [1] P. Trtik and P. J. M. Bartos. Micromechanical properties of cementitious 578 composites. Materials and Structures, 32(5):388-393, 1999.

579 [2] P. Acker. Micromechanical analysis of creep and shrinkage mechanisms. In 580 Creep, shrinkage and durability mechanics of concrete and other quasi-brittle 581 materials. (Proceedings of ConCreep6), 2001.

582 [3] K. Velez, S. Maximilien, D. Damidot, G. Fantozzi, and F. Sorrentino.

583 Determination by nanoindentation of elastic modulus and hardness of pure constituents 584 of portland cement clinker. Cement and Concrete Research, 31(4):555 - 561, 2001.

585 [4] G. Constantinides, F.-J. Ulm, and K. Van Vliet. On the use of nanoindentation 586 for cementitious materials. Materials and Structures, 36(3):191-196, 2003.

587 [5] G. Constantinides and F.-J. Ulm. The effect of two types of c-s-h on the 588 elasticity of cement-based materials: Results from nanoindentation and 589 micromechanical modeling. Cement and Concrete Research, 34:67-80, 2004.

590 [6] J. J. Chen, L. Sorelli, M. Vandamme, F.-J. Ulm, and G. Chanvillard. A coupled 591 nanoindentation/sem-eds study on low water/cement ratio portland cement paste:

592 Evidence for c-s-h/ca(oh)2 nanocomposites. Journal of the American Ceramic Society, 593 93(5):1484-1493, 2010.

594 [7] M. Vandamme and F.-J. Ulm. Nanoindentation investigation of creep properties 595 of calcium silicate hydrates. Cement and Concrete Research, 52:38 - 52, 2013.

596 [8] W.C. Oliver and G.M. Pharr. An improved technique for determining hardness 597 and elastic modulus using load and displacement sensing indentation experiments. 598 Journal of Materials Research, 7:1564-1583, 1992. 
600 indentation techniques for hydrated nanocomposites: Concrete, bone, and shale. Journal 601 of the American Ceramic Society, 90:2677-2692, 2007.

602 [10] L. Sorelli, G. Constantinides, F.-J. Ulm, and F. Toutlemonde. The nano603 mechanical signature of ultra high performance concrete by statistical nanoindentation 604 techniques. Cement and Concrete Research, 38(12):1447 - 1456, 2008.

605 [11] C. Hu, Y. Gao, Y. Zhang, and Z. Li. Statistical nanoindentation technique in 606 application to hardened cement pastes: Influences of material microstructure and 607 analysis method. Construction and Building Materials, 113:306 - 316, 2016.

608 [12] P. Trtik, B. Münch, and P. Lura. A critical examination of statistical 609 nanoindentation on model materials and hardened cement pastes based on virtual 610 experiments. Cement and Concrete Composites, 31(10):705 - 714, 2009.

611 [13] F.-J. Ulm, M. Vandamme, H. M. Jennings, J. Vanzo, M. Bentivegna, K. J. 612 Krakowiak, G. Constantinides, C. P. Bobko, and K. J. Van Vliet. Does microstructure 613 matter for statistical nanoindentation techniques? Cement and Concrete Composites, $614 \quad 32(1): 92-99,2010$.

615 [14] D. Davydov, M. Jirásek, and L. Kopecký. Critical aspects of nano-indentation 616 technique in application to hardened cement paste. Cement and Concrete Research, $61741(1): 20-29,2011$.

618 [15] P. Lura, P. Trtik, and B. Münch. Validity of recent approaches for statistical 619 nanoindentation of cement pastes. Cement and Concrete Composites, 33(4):457 - 465, 6202011.

621 [16] P. Mondal, S. P. Shah, and L. Marks. A reliable technique to determine the local 622 mechanical properties at the nanoscale for cementitious materials. Cement and Concrete 623 Research, 37(10):1440 - 1444, 2007. 
624 [17] J. J. Hughes and P. Trtik. Micro-mechanical properties of cement paste 625 measured by depth-sensing nanoindentation: a preliminary correlation of physical 626 properties with phase type. Materials Characterization, 53:223 - 231, 2004. EMABM 627 2003: 9th Euroseminar on Microscopy Applied to Building Materials.

628 [18] C. Hu and Z. Li. Micromechanical investigation of portland cement paste. 629 Construction and Building Materials, 71:44 - 52, 2014.

630 [19] W. Zhu, J. J. Hughes, N. Bicanic, and Chris J. Pearce. Nanoindentation mapping 631 of mechanical properties of cement paste and natural rocks. Materials Characterization, $63258: 1189-1198,2007$. 10th Euroseminar on Microscopy Applied to Building Materials 633 (EMABM).

634 [20] S. Zhao and W. Sun. Nano-mechanical behavior of a green ultra-high 635 performance concrete. Construction and Building Materials, 63:150 - 160, 2014.

636 [21] M. Vandamme, F.-J. Ulm, and P. Fonollosa. Nanogranular packing of C-S-H at 637 substochiometric conditions. Cement and Concrete Research, 40(1):14 - 26, 2010.

638 [22] A. B. Nichols and D. A. Lange. 3d surface image analysis for fracture modeling 639 of cement-based materials. Cement and Concrete Research, 36(6):1098 - 1107, 2006.

640 [23] T. Ficker, D. Martisek, and H. M. Jennings. Roughness of fracture surfaces and 641 compressive strength of hydrated cement pastes. Çement and Concrete Research, $64240(6): 947-955,2010$.

643 [24] B. Hilloulin, J.-B. Legland, E. Lys, O. Abraham, A. Loukili, F. Grondin, O. 644 Durand, and V. Tournat. Monitoring of autogenous crack healing in cementitious 645 materials by the nonlinear modulation of ultrasonic coda waves, $3 \mathrm{~d}$ microscopy and $\mathrm{x}$ 646 ray microtomography. Construction and Building Materials, 123:143 - 152, 2016. 
647 [25] Q. Zhang, R. Le Roy, M. Vandamme, and B. Zuber. Long-term creep properties

648 of cementitious materials: Comparing microindentation testing with macroscopic

649 uniaxial compressive testing. Cement and Concrete Research, 58:89 - 98, 2014.

650 [26] M. Irfan-ul-Hassan, B. Pichler, R. Reihsner, and Ch. Hellmich. Elastic and creep 651 properties of young cement paste, as determined from hourly repeated minute-long 652 quasi-static tests. Cement and Concrete Research, 82:36 - 49, 2016.

653 [27] D.-T. Nguyen, R. Alizadeh, J. J. Beaudoin, P. Pourbeik, and L. Raki. 654 Microindentation creep of monophasic calcium-silicate-hydrates. Cement and Concrete 655 Composites, 48:118 - 126, 2014.

656 [28] J. Frech-Baronet, L. Sorelli, and J.-P. Charron. New evidences on the effect of 657 the internal relative humidity on the creep and relaxation behaviour of a cement paste by 658 micro-indentation techniques. Cement and Concrete Research, 91:39 - 51, 2017.

659 [29] K.G. Field, I. Remec, and Y. Le Pape. Radiation effects in concrete for nuclear 660 power plants - part i: Quantification of radiation exposure and radiation effects. Nuclear 661 Engineering and Design, 282:126 - 143, 2015.

662 [30] Y. Le Pape, K.G. Field, and I. Remec. Radiation effects in concrete for nuclear 663 power plants, part ii: Perspective from micromechanical modeling. Nuclear Engineering 664 and Design, 282:144 - 157, 2015.

665 [31] A. Giorla, M. Vaitová, Y. Le Pape, and P. Štemberk. Meso-scale modeling of 666 irradiated concrete in test reactor. Nuclear Engineering and Design, 295:59 - 73, 2015.

667 [32] H. K. Hilsdorf, J. Kropp, and H. J. Koch. The effects of nuclear radiation on the 668 mechanical properties of concrete. Technical report, ACI SP-55, 1978.

669 [33] ANDRA. Dossier 2005 argile, architecture and management of a geological 670 repository. Technical report, ANDRA, 2005. 
671 [34] P. Soo and L. M. Milian. The effect of gamma radiation on the strength of

672 portland cement mortars. Journal of Materials Science Letters, 20(14):1345-1348, 6732001.

674 [35] F. Vodák, K. Trtík, V. Sopko, O. Kapicková, and P. Demo. Effect of $\gamma$ 675 irradiation on strength of concrete for nuclear-safety structures. Cement and Concrete $676 \quad$ Research, 35(7):1447 - 1451, 2005.

677 [36] O. Kontani, Y. Ichikawa, A. Ishizawa, M. Takizawa, and O. Sato. Irradiation 678 effects on concrete structures. In International Symposium on the Ageing Management 679 \& Maintenance of Nuclear Power Plants, 2010.

680 [37] O. Kontani, S. Sawada, I. Maruyama, M. Takizawa, and O. Sato. Evaluation of 681 irradiation effects on concrete structure - gamma - ray irradiation test on cement paste. 682 In Proceedings of the ASME 2013 Power Conference (POWER2013), July 29-August 1, 683 2013, Boston, Massachusetts, USA, 2013.

684 [38] A. Lowinska-Kluge and P. Piszora. Effect of gamma irradiation on cement 685 composites observed with XRD and SEM methods in the range of radiation dose 0 6861409 MGy. Acta Physica Polonica, A, 114:399 - 411, 2008.

687 [39] D. McDowall. The effects of gamma radiation on the creep properties of 688 concrete. In Proceedings of the Information Exchange Meeting on 'Results of Concrete 689 Irradiation Programs', EUR 4751 f-e, Commission des Communautés Européennes, 690 Brussels, Belgium, 1971.

691 [40] R.L. Grossman, C. Kamath, P. Kegelmeyer, V. Kumar, and R. Namburu. Data 692 Mining for Scientific and Engineering Applications. Springer US, 2001.

693 [41] Krishna Rajan. Materials informatics. Materials Today, 8(10):38 - 45, 2005.

694 [42] J.H. Koo. Polymer Nanocomposites: Processing, Characterization, and 695 Applications. McGraw-Hill, New York, 2006. 
696 [43] S. K. Barai. Data mining applications in transportation engineering. Transport, 697 18(5):216-223, 2003.

698 [44] F. Vodák, V. Vydra, K. Trtík, and O. Kapiccková. Effect of gamma irradiation 699 on properties of hardened cement paste. Materials and Structures, 44:101 - 107, 2011.

700 [45] M. Miller, C. Bobko, M. Vandamme, and F.-J. Ulm. Surface roughness criteria 701 for cement paste nanoindentation. Cement and Concrete Research, 38(4):467 - 476, 7022008.

703

704 